\title{
$O$ artigo definido e os numerais na língua Kirirí: Vocabulários Português-Kirirí e Kirirí-Português
}

\author{
Aryon Dall'Igna Rodrigues ${ }^{1}$
}

Uma das poucas gramáticas que existem de línguas indígenas da América do Sul, é a Arte de Gramática da Língua Brasílica da Nação Kirirí, composta pelo Pe. Luís Vincêncio Mamiani, no ano de 1699. Embora um tanto complicada, como soem ser essas gramáticas moldadas à latina, é bastante detalhada, e nos dá uma perfeita ideia da sintaxe dessa língua.

Utilizando-me de um exemplar da $2{ }^{\text {a }}$ edição, impressa pela Biblioteca Nacional, em 1877, tenho feito comparações lexicais com outros idiomas americanos, assim como organizei os vocabulários português-Kirirí e Kiriríportuguês, aproveitando não só as palavras que na $2{ }^{a}$ edição vêm ordenadas, como também as que se encontram intercaladas em frases, principalmente na 2. ${ }^{\mathrm{a}}$ parte.

A fim de poder extrair as palavras que se encontram nas frases, tive que observar bem as regras gramaticais, para bem decompor essas frases. E assim observei a existência do artigo definido, a qual demonstro abaixo, assim como pude também, em parte, analisar os numerais.

\footnotetext{
1 É com prazer que apresento aos leitores dos “Arquivos" o nome do jovem Aryon Dall'Igna Rodrigues, meu aluno que foi no Ginásio Paranaense, e meu discípulo nos estudos linguísticos e especialmente de glotologia americana. Já publicou no "Ginásio Paranaense - Externato" os seguintes ensaios: "Diferença entre as Línguas Tupí e Guaraní" (7-940), "Língua Brasílica" (8 e 9-940), "Os Nomes do Rio Amazonas" (10 e 11-940), "Idiotismos da Língua Tupí" (4-941), e "A Influência Portuguesa na Sintaxe Nheengatú" (11-941). Trabalhos breves, não há dúvida, mas em que se entrevê a realidade futura de um valoroso americanista.

O presente estudo - - "O Artigo Definido e os Numerais na Língua Kiriri” — demonstram já a firmeza e a probidade das suas conclusões.

Da "Gramática Kirirí" do Pe. Mamiani elaborou, por ordem alfabética, para seu uso, os vocábulos aí espalhados, e teve a gentileza de tirar uma cópia para mim. Foi então que tive a ideia da publicação desse vocabulário nos "Arquivos". Pedi-lhe que organizasse a parte kirirí-portuguesa, e, prontificando-se de boa vontade, prestou assim relevante serviço ao indianismo nacional.

Saberão estimar o valor deste trabalhoso mister, principalmente os comparativistas, e, então, o seu organizador sentir-se-á bem compensado, por ter-se tornado muito útil à ciência.

R. F. MANSUR GUÉRIOS, assistente de Linguística no M. P.
} 


\section{Artigo definido}

Exercendo a função de artigo definido encontra-se a partícula dó, à qual o Pe. Mamiani atribui unicamente a função de preposição $a$, para, e também de.

Vê-se, porém que não é preposição em frases como: Suipabó do dibuânguetésó waré, confessa teus pecados ao padre; sodé a-keicó do e-buengueié do waré?, por que encobris os pecados ao padre? Em ambas as frases diz o Pe. Mamiani haver dois casos: na primeira um com a preposição dó e outro com a preposição só, caso especial dos verbos ipabó e mé, confessar-se e falar, respectivamente; na segunda ambos os casos com a preposição dó. Porém, traduzindo-se as frases literalmente, sendo dó preposição, tem-se: "confessa para seus pecados para padre" e "porque encobres para teus pecados para padre?", o que é completamente sem nexo. Mas tomando-se dó como artigo definido (na 2. ${ }^{\text {a }}$ frase só o primeiro), tem-se: "confessa os seus pecados para (o) padre" e "porque encobres os teus pecados para (o) padre?", o que é inteiramente compreensível.

A partícula dó considerada como artigo definido explica melhor o caso da "primeira casta de substantivos que sai da regra geral dos possessivos." Diz Mamiani que a esta casta pertencem os substantivos que não recebem imediatamente os possessivos, e sim mediante outro substantivo genérico. Por exemplo, os nomes de animais que se criam em casa recebem os possessivos mediante o substantivo enkí, criação; assim para dizer minha vaca, diz-se $h i$ enkí do cradzó. Os nomes de coisas cozidas tomam os possessivos mediante o substantivo udé, que significa coisa cozida, e para dizer - meus feijões cozidos, diz-se $d z$-udé do guinhé (compare-se o tupí: xé-reimbâba tapiîra, minha vaca (Anchieta, f.14, v.); no tupí não há absolutamente o artigo definido, e aqui reimbâba está exatamente no mesmo caso que enkí no Kirirí).

Tomando-se dó como artigo definido, melhor se traduz essas frases assim: "minha criação, a vaca" e "meu cozido, os feijões".

A este caso creio que pertencem os exemplos citados na página 50, exceção primeira à regra da colocação de dois substantivos, sendo um deles genitivo. São os exemplos: aribá do bunhá, prato de barro, e burehé do masichi, papas de milho. Segundo Mamiani dó é preposição (de), sendo a construção semelhante à portuguesa. Creio, porém, que também aqui dó é artigo definido, do mesmo modo que no caso dos possessivos, acima citado.

Para se dizer- minhas papas de milho, diz-se: $d z u$-burehé do masichi, e para - meu prato de barro, diz-se: hi-aribá do bunhá. Estas formas bem podem ser traduzidas assim, respectivamente: "minhas papas, o milho" e "meu prato, o barro". Como se vê é o mesmo modo de dizer que caracteriza a "primeira casta de substantivos que sai da regra geral dos possessivos".

Mais um caso em que o artigo definido dó é pelo Pe. Mamiani denominado preposição, e por tal traduzido, é este: s-ucá inhurae do dipadzú, o filho ama $a$ 
seu pae; creio ser "o filho ama o seu pae", também em razão de o verbo, amar ser mais comumente transitivo direto.

Outro exemplo, no qual, porém, o Pe. Mamiani não traduz a "preposição": moré si-té caraí do hi-padzú, logo vem o branco, meu amo; deve ser: logo vem (o) branco, o meu amo (contudo Batista Caetano crê ser: logo vem o branco, o qual é meu amo).

Fica visto pois que nesses casos todos a palavra dó é artigo definido, e não preposição. Ser dó preposição $a$, e ao mesmo tempo artigo definido, é uma coincidência exatamente como a que se dá no português em ser $a$ artigo definido e ao mesmo tempo preposição.

Este artigo definido, porém, não se emprega em todos os casos em que é empregado o artigo português. E aqui vão algumas regras observadas sobre o não emprego do artigo definido:

$1 .^{\circ}$ - Não se emprega o artigo definido após as preposições: tecri idzené dumarã, veio por medo do inimigo (inimigo - dumarã); inhá ipenehó waré, morreu à vista do padre (padre - waré; ipenehó - à vista de); sodé a-keicó dó e-buângueté dó waré?, por que encobres os pecados ao padre? (waré - padre; dó - para, a).

2. ${ }^{\circ}$ - Não se emprega o artigo definido após os demonstrativos: erí tapanhú, este é o negro (negro - tapanhú).

3. ${ }^{\circ}$ - Não se emprega o artigo junto aos adjetivos: buângue caraí, o branco é mau (branco - caraí); chedé sutú, a fruta está madura (fruta - sutú; chedémadura).

$4 .^{\circ}$ - Não se emprega o artigo entre o verbo e o sujeito: s-ucá inhuræ do dipadzú, ama o filho o seu pai (filho - inhuræ); pacri cradzó hi-nhá, foi morta a vaca por mim (vaca-cradzó); moré si-té caraí do hi-padzú, logo vem o branco, o meu amo (branco - caraí).

Há escassez de exemplos para comprovar; entretanto, com o pouco encontrado, chego quase a afirmar que só é o artigo definido empregado após os substantivos e verbos (nestes últimos, salvo o quarto caso de não emprego, acima exposto), sendo que todas as outras categorias gramaticais o repelem.

\section{Os numerais}

Dá o Pe. Mamiani os números de 1 a 10 e o 20. São eles: 1 bihé, 2 wacháni, 3 wachánidikié, 4 sumarã oróbæ, 5 my bihé misã saí, 6 myreprí bubihé misã saí, 7 myreprí wacháni misã saí, 8 myreprí wachánidikié misã saí, 9 myreprí sumarã oróbæ misã saí (Mamiani omitiu a palavra misã), 10 mycribæ misã saí, 20 mycribæ misã idehó iby saí.

Procurei interpretar os significados desses números e cheguei ao seguinte resultado: 
1 e 2 - números simples;

3 - composto de wacháni, dois; para o termo dikié, não consegui encontrar significação, senão decompondo em $d y$-kié, não-não, o que não pode adaptarse ao presente caso;

4 - não consegui interpretar o significado (sumarã significa "seu inimigo");

5 - não consegui atinar com o sentido dessa partícula $m y$, que precede todos os números maiores que este, a qual parece nada representar ${ }^{2}$; creio que saí seja "dedo" e, portanto, bihémisã saí signifique "dedos de uma mão" (misã, mão; bihé, um; quanto à composição misã saí, "dedos da mão", veja-se na p. 51 da Gramática os compostos ipo-cú, lágrimas e tçambú-sebé, cobertura da cabeça);

6 - ignoro o que seja myreprí, ou melhor reprí; porém é esta palavra que faz variar o sentido da expressão, fazendo com que, por exemplo, (myreprî) wachánimisã saí seja "dois e os dedos da mão", e não "dedos de duas mãos"; $b u$ é uma das partículas que acompanham os adjetivos, e que vêm citadas à página 53; bihé, um; misã saí, dedos da mão; o conjunto pois deve ser: um e os dedos da mão;

7 - dois e os dedos da mão;

8 - três e os dedos da mão;

9 - quatro e os dedos da mão;

10- cribae significa "todos"; portanto: todos os dedos da mão (mãos) (notese a ausência do vocábulo reprí, com o qual deveria ser "todos e os dedos da mão (mãos)");

20 - my,?; cribae, todos; misã, mãos; idehó, com; iby, pés; saí, dedos; a proposição: todos os dedos das mãos com os pés.

Nota a respeito da grafia e citação dos exemplos - A grafia conservei-a neste trabalho quase a mesma de Mamiani, salvo ligeiras alterações, que são: o $y$ com acento circunflexo ( $\left.{ }^{\wedge}\right)$ de Mamiani (= y vogal do tupí) aqui grafo $y$ simplesmente, pois não há perigo de ser confundido com o $y$ (semiconsoante) porque ele (o com acento circunflexo) nunca precede outra vogal. O gh substitui por $g u$; o acento grave pelo acento agudo. Quanto ao citar dos exemplos, sempre dou a tradução de Mamiani, como p. ex.: sodé a-keicódo e-buangueté do waré?, porque encobris os pecados ao padre? O verbo está na 2 . $^{a}$ pessoa do singular, e o substantivo buangueté está precedido pelo pronome da 2 . $^{\text {a }}$ pessoa do singular; contudo conservo a tradução original, indo dar a exata só adiante,

2 Pode ser um designativo dos numerais. 
quando cito a minha. Assim agi nos demais exemplos.

\section{Vocabulários Português-Kirirí e Kirirí-Português}

De acordo com a classificação de Paulo Rivet, está a língua Kirirí filiada à XXVIII família linguística sul-americana, a família Cariry: "XXVIII. Família Cariry (Karirí). A família Cariry ocupa um vasto território a norte e a oeste do rio S. Francisco nos Estados da Baía, Pernambuco, Piauí, e Ceará. Esta família compreende: os Carirys propriamente ditos (Kirirí, Kayrirí) e os Sabuyás" (J. Bertolaso Stella, "As Línguas Indígenas da América”, p. 69).

Os presentes vocabulários da língua Kirirí, como já disse anteriormente, organizei-os eu, extraindo os vocábulos que se encontram na 2. ${ }^{a}$ edição da "Arte de Gramática da Língua Brasílica da Nação Kiriri”, do Pe. Luís Vicêncio Mamiani, tanto na $1 .^{\mathrm{a}}$ como na $2 .^{\mathrm{a}}$ parte.

Além desta "Arte de Gramática", publicou Mamiani um "Catecismo da Doutrina Cristã na Língua Brasílica da Nação Kirirí”, o qual infelizmente não conheço.

Na parte português-Kirirí consegui 860 vocábulos, e na Kirirí-português apenas 800 . É esta diferença devida ao fato de haver no Kirirí muitas palavras e partículas de múltiplos sentidos, bem como por se terem dado várias repetições na primeira parte.

Procurei tornar este trabalho o mais prático possível aos consultantes, que, certamente, mais o usarão para confrontos com outros idiomas. Por este motivo, na parte português-Kirirí, sempre procurei colocar em primeiro plano a parte mais importante da expressão, como p. ex.: baixo, para, de (para baixo, de baixo), cheirado, ser (ser cheirado), etc. Este modo de colocar pode eventualmente trazer alguma dúvida ao consultante; neste caso aconselho-o a confrontar a parte Kirirí-português.

Antes dos vocabulários darei o valor do alfabeto adotado por Mamiani, e juntamente citarei as modificações que nele fui levado a fazer, afim de que o trabalho se adaptasse às possibilidades da tipografia.

O ditongo æ representa uma vogal "entremeia entre o $a$ e o $e$; e se pronuncia com um som diverso das outras vogais, ou como $a$ fechado que participa do $e$, ou como $e$ largo que participa do $a$ "(sic).

$\mathrm{O} d$ às vezes se pronuncia tão brandamente, que apenas se conhece, como nas palavras: ide, mãe; udje, legumes.

O g sempre é velar, sendo seguido de $h$ antes de $e, i$ e $y$ (com acento circunflexo); como aqui substituí o $y$ acentuado com o circunflexo pelo $\ddot{u}$, só será o gh encontrado antes de $e$ ei. Diz o Pe. Mamiani que é o $g$ pronunciado brandamente, com aspiração na garganta, de modo que mal se nota, quando vier ele acentuado com o acento circunflexo, como nestas palavras: gü, ser 
cheirado; inghe, criança; rhenge (?), velho. Não se encontra, entretanto, nem nestes exemplos, nem no resto da Gramática, nenhum g com acento circunflexo.

$\mathrm{O} h$ "com as vogais e consoantes sempre é aspiração gutural; exceto quando segue ao $e$ e $n$, porque então faz como no português, nas sílabas cha, che, nha, nhe. Esta aspiração é muito usada nesta língua, por ser muito gutural: mas para evitar a multiplicidade desta letra em todas as palavras, que poderia causar confusão, usamos dela na escritura somente entre as vogais, e a deixamos nas consoantes; e para que sirva de regra geral, que as consoantes $t$ e $p$ pedem mais ordinariamente a aspiração do que as outras, como o uso e a praxe ensinará melhor".

O $y$ representa o $i$ semiconsoante; o $y$ com acento circunflexo (que aqui substituo pelo $\ddot{u}$ ) representa o "i grosso" do tupí, geralmente representado pelo $y$ (p. ex.: $y$, água, py, pé).

$\mathrm{O} w$ se pronuncia "com um som misto de dois $v v$, dos quais o segundo fica líquido, e o primeiro como consoante: v.g. Warè, Padre”.

$\mathrm{O}$ acento circunflexo indica que as vogais "se hão de pronunciar com som gutural na garganta, ou com som grosso com os beiços fechados. Desse modo sobre o $a$, denota que se há de pronunciar com um som que participa do $a$ e $o$, e se faz pronunciando o $a$ com os dentes fechados: v.g. Sâmbá, cagado. Sobre o $e$ faz um $e$ estreito, e se forma fechando do mesmo modo os dentes: v.g. Woyên, tapuias bravos". "Sobre o $o$ faz também um $o$ estreito, pronunciado com os beiços fechados: v.g. Pôhô, varge". (sic).

Note-se ainda que Mamiani diz utilizar-se do acento agudo - "usamos de dois acentos, um agudo e outro circunflexo" (p. 4); entretanto, salvo algumas exceções, vêm todos os vocábulos acentuados com acento grave, em vez de agudo, e aqui reproduzo o grave, conservando o agudo só naquelas exceções.

Também dispensei a cedilha na letra $c$, quando esta precede $e$ ou $i$.

Um ${ }^{\mathrm{n}}$ bem minúsculo, acima da linha, à direita da vogal e, substitui o til, que há em Mamiani.

As letras aqui não citadas têm o mesmo valor que em português.

NOTA - Os números entre parênteses, após os vocábulos, indicam a página da "Arte de Gramática" em que se encontram esses vocábulos. A abreviatura Lat. indica o termo latino equivalente ao citado. As reticências intercaladas em um vocábulo indicam que a palavra que por ele deve ser regida ou determinada, fica nele intercalada; p. ex.: a... a, vosso: $a$-bürò-à, vossa barriga. 


\section{PORTUGUÊS-KIRIRÍ}

\section{A}

A, contra (Lat. VERSUS) - Aİ $(20,84)$, SÒ $(84,87)$.

A, para (dativo) - DÒ (85).

Abano - WIMÀ (25).

Aboiar - WOICRÆBAHÀ (30).

Acenar com a cabeça - $\operatorname{WINÈ~}(29,80)$.

Acenar com a mão - RAEn BÒ (80).

Achado, coisa achada - UITÒ (60).

Açoitar - BÜSAPRİ $(63,64,71)$.

Acolá - DEHEn TCI (92), MOROHÒ (93).

Acometer - DÒ (80).

Acordar - POTÇÒ (29).

Admiração, ver com - WORYOENTÀ (79) (Com certeza está por WOROYENTÀ; v. abaixo).

Admirar o que se vê - WOROYENTÀ (35).

Afiado - YANÈ (99). (Contudo na p. 52 vem - SIRIYANETÈ).

Afligir-se - DZEYÀ (77).

Agastar-se - RÈ $(29,80)$.

Agora - DO IGÜ (92).

Agourar mal - BUKERI (35), UBUKERI (79).

Agradável, ser - ITU் (80).

Água - DZÙ (15).

Água do rio - IWODZÙ (76).

Aguilhada - TAMÜ (24).

Agulha - AWİ (22).

Ai! (Lat. HEU, miserentis) - HOMÓRÒ (97).

Ai! (Lat. HEU, ingemiscentis) - HÈ (96). 
Ai! (Lat. HEU, dolentis; voz de mulher) - AGÀ, AGANORI (96).

Ai (Lat. HEU, dolentis; voz de homem) - YAHE (97).

Ainda que - PROH (98).

Aio - DUBÈ (15).

Alcofa - TINHÈ (24).

Alegrar-se - USE (79), (33).

Além - PRODENHÈ, PRODENHÈMÜ (87)

Alevantar-se, e ir-se - TIHIWI (34).

Alfange - CRÆ (23).

Algibeira - BOCÒ (14).

Algodão - ENDI (23).

Alguidar - BUBEn ${ }^{\mathrm{n}} \mathrm{HÒ} \mathrm{(22).}$

Alma - ANHI (19).

Alta noite - CAYADÈ (92).

Alto - HECHI (57).

Alvo, limpo - KENKÈ (53), BUCÙ (95).

Amanhã - CARATCI (92).

Amanhã, depois de - CAYEn HOHÒ (92).

Amar - UCÀ $(34,79)$.

Amarelo - ERÃ (53).

Amarrilho, correr o - CRARAIWI (32).

Amigo - RENDÈ $(50,64)$.

Amo - PADZÙ (50), SE (65).

Amores, andar de - PONHÈ (80).

Andar errado do caminho - WONGHEBÜ (81).

Andar de cócoras - DADAWI (33).

Anteontem - CAYAHOHÒ (92).

Antes que - TA (90).

Antigamente - KENHÈ (93).

Anzol - YACRORÒ (16). 
Aonde? - MODÈ? (88).

Apertadamente - TÇÃ (91).

Após, atrás - WOBOHÒ (87).

Apressar-se - ÆMBURE (27).

Apressa-te - BROCÀ (46).

A que? Para que? - SAIDÈ? (88).

Aquele - ROHÒ (9).

Aqui - MOIGÜ (93).

Aqui mesmo - MOIHÜDZÃ (por MOIGÜDZÃ) (93).

Aqui, eis - MOIGÜNÈ (93).

Arco - SERIDZÉ (24).

Areia - KITCI (2).

Arrebentar fio - TAPRİ (34).

Arrebentar as plantas - SÃICRÒ (33).

Arreganhar os dentes - YACRİ (33).

Arrelá! (Lat. APAGE, voz de homem) - ARİ (96).

Arrepiar-se o cabelo - TCICRÆ (29).

Arriba, em cima - YEMÜ (92).

Arribar - IDABÀ (33).

Arrotar - NECÒ, NECOTÒ (29).

Assado, coisa assada - UPODÒ (60).

Assado em covas - CREYÀ (23).

Assentar-se - DADI (33).

Assim - MORÒ (93).

Assim, aí, dessa maneira (Lat. HUJUSMODI)- MORI, MORINÈ (88)

Assim como digo - BERÒ (91).

Assim será, assim farei - HOMODIRODI (92).

Assim é? (Lat. ITANE?) - HOMONO? (92).

Assobiar - EBAYASİ, BAYASİ $(31,35)$.

Assobio de rabo de tatú - TÇUIRÙ (24). 
Até agora - DO IGÜCHI (92).

Até aqui - MOIGÜCHI (93).

Até lá, não mais (Lat. USQUE) - CHI (89).

Atolar - TOWANHIDÒ (29).

Atrás - WOBOHÒ (87).

Atrever-se - WINÙ (79).

Avisar - KENDÈ (28, 79).

Avó - NHIKÈ (17), TÒ (18).

Azedo - WÂTÍ (20).

Azul - CRACÙ (53).

\section{B}

Baixa, em parte (Lat. INFERNE) - SAIBAMÜ (93).

Baixo, para, de (Lat. INFERIUS) - RADAMÜ (93).

Balaio - BARÀ (22).

Balça - EYEMÈ (21).

Baldadamente - MOHOTÇÃ, MOHETÇÃ $(5,93)$.

Banana - BACOBÀ $(13,60)$.

Banco - PÜCÀ (17).

Banquete - ICÙ (77).

Barba - ENÀ (21).

Barriga - BÜRÒ (22).

Barro - BUNHÀ $(50,76)$.

Basta (Lat. SAT EST) - MORO, MORONÒ (93).

Bater - PO (90).

Bêbado - WODÒ (18).

Beijú - WARÆRÒ (25).

Beira - BE (13).

Bem (Lat. RECTE) - WONHÈ (91), CANGHI (67). 
Boa obra, coisa - CANGHITÈ (14).

Boca - WARIDZÀ (25).

Boca da noite, à - KIERETÙ (93).

Bocejar - BIDZONCRÀ (27), YACRÈ (33).

Boi - CRADZÒ $(5,7)$.

Bolo de mandioca assada - WARUDÙ (25).

Bolor - KÜDI (16).

Bom (adj.) - CANGHI (65).

Bom (subst.) - DICANGHIRI (82).

Bondade - BUONHETÈ (14).

Bordão - BÆTÒ (13), TOTONGHI (25).

Botar - TI (90).

Braço - BÒ $(14,51)$.

Braço de rio, caminho, etc. - WORÈ (19).

Branco (cor) - CÙ (53).

Branco (homem) - CARAİ $(50,101)$.

Brigar - WODICÒ (30).

Brincar - BENHEKIÈ (32).

C

Cá, para - CATCIHÒ (92).

Cabaço - BUIBÙ (22).

Cabeça - TÇAMBÙ (18).

Cabeça, cobertura da - TÇAMBÚSEBÈ (51).

Cabeça, fontes da - BEBÀ, BEBATÈ (13).

Cabelo - DÜ (15).

Cabo de instrumento - BEDZÈ (13).

Caça (animal) - ADJE, ADJÈ $(83,100)$.

Cachaporra - TÇONCUPÜ (18). 
Cachimbo - PÆWI (17).

Cachorro - YACÀ (96).

Cacimba - CRAYOTÈ (23).

Caco - BENÃ (13).

Cadeiras - SEBÜ (24).

Cagado - SÂMBÁ (4).

Cair - BÜPRÒ (32), DZI (33).

Cair a árvore - PROWI (33).

Caixa - CRAMEMÙ (15).

Calcanhar - BÆRÙ (13).

Camarada - RENDÈ (50).

Caminhar - Wà (46).

Camerada mulher - DZIDÈ (15).

Caminhar - WÒ

Caminho - WÒ (46).

Campo - MERÀ (18).

Canafrecha - TINGHI (18).

Canela da perna - EBEYÀ (16).

Cantiga - MARA (20).

Capim - PÜ (3).

Capoeira, roçado velho - BUCUNÙ (22).

Cara - BIDZANCRÒ (14).

Carga - E $(16,61)$.

Carga aos ombros - DAMÜ (23).

Carimã - SEKIKI (24).

Carne (de boi) - CRADZÒ (57).

Carne salgada - RINÈ (24).

Caroço - CÒ $(14,51)$.

Carro - IBÀ (23).

Carta - TORARÃ (25). 
Cãs - BUCUTÈ (14).

Casa - ERÀ (20).

Casamento - PIWONHÉ (80).

Casar - PIWONHÈ (81), PI (63).

Casca - BURÒ (14).

Cavaco - HENANDZİ (16).

Cavador - DEHEBÀ (15).

Cavalgar pau - WOICRÆ (30).

Cavalo - CABARÙ (86).

Cerca de paus - DEDI (23).

Certamente - BERÒ (91), HOMO, HOMOBERÒ (92).

Cesto - SETÙ (24).

Céu superior - ECUWÕBUYEn ${ }^{\mathrm{n}}$ (23).

Chaga - BEHẼ, BEHETÈ (13).

Chamar por alguém - CÀ (80).

Chamuscar, tomar chamusco o comer - KETÇÃ (28).

Chão - RADA (77).

Chegar com a mão - BÆIWI (27).

Chegar com o corpo - BETÈ $(27,80)$, BÆWI (80).

Cheirado, ser - GÜ (2).

Cheiro, lançar - ANDI (31).

Chorar - ENKÈ (33).

Chover - TIDZÒ (34).

Chuviscar - TINHECÙ (34).

Chuva - DZÒ (76).

Cidade - ERÀ BUYEn (74).

Cinco - MÜ BIHÈ MISÃ SAÍ (6).

Cinza - BÜDI (14).

Ciúmes, ter - WONHÙ $(30,80)$.

Clara de ovo - MAIBÀ (23). 
Claramente, inteligivelmente - WORONÈ (91).

Claro - NÈ, NÙ (53).

Coalhar-se - DENÃ (28).

Cobertura - SEBÈ (51).

Cobra - WÒ (?) Na frase: NO HIWI MO BECHE ${ }^{\mathrm{n} O}$ Õ HIETÇÃ NO WÓ - Indo para a roça me mordeu uma cobra (74).

Cofo - CRUDZÃ (15).

Colar de osso - BEBÀ (22).

Colher (subst.) - CUROTÈ (23).

Com (de companhia, cúmplice) - DEHÒ, EMBOHÒ $(19,85)$.

Com (de carga, cargo, cuidado) - MANDI $(20,86)$.

Coma (subst.) - KIECHI (16).

Combetear (?) - WIRE (34).

Comer carne, ter desejo de - EIBARÙ (28).

Comer que se guarda - COTÒ (23).

Comida - AMÎ (20).

Comigo - HIEMBOHÒ (7).

Compaixão, causar - NHIKIENGHI, NHIHIENGHI (?) $(29,80)$.

Comprido - CHI (53).

Concebido, ser - YAHI (30).

Confessar-se - IPABÒ $(35,79)$.

Conosco (exclus.) - HIEMBÓHODE (7).

Conosco (inclus.) - KEMBOHÒ.

Conserto de ferramenta - INIÒ (23).

Considerado, ser - NETÒ (30).

Consigo (c/ ele) - SEMBOHÒ (9).

Consigo (c/ eles) - SEMBOHOÀ.

Consolar-se - CROTÇÃBÜ (28).

Contado, narrado, ser - BENHÈ (30), PERÈ (80).

Contar - WOROBÜ (35). 
Contas - MÜGÜ (16).

Contigo - EYEMBOHÒ.

Continuadamente - IDADÈ, RONÈ (90).

Contra - Aİ, SÒ $(20,84,87)$.

Contudo - IBÓNÒ (98).

Convosco - EYEMBOHOÀ.

Coração - SI (17).

Corcovado - TCETÒ (18).

Corda - DZITÙ (23).

Cordão - SETI (24).

Corpo - BUYEn'WOHÒ (14).

Corpo, juntas do - ECUDÙ (21).

Correr - BÜ (27).

Corrupio - TERERÈ (24).

Cortar - POTE (90), TÇATE (2).

Cortesia com o pé - TORÀ (24).

Cortesia, fazer - TIDACRÙ (29), TORÀ (35).

Costas - WORÒ (19).

Cotovelo - PÒ-IBÒ, BOROPÒ (52).

Cozido, coisa cozida - UDÈ (59).

Criação - ENKI (20, 50).

Criança - INGHE $(2,23)$,

Crista de galo - NHEPRÙ (17).

Crueiras da mandioca - EYAPÒ (23).

Cuia - CROBECÀ (15).

Cuidado, dar - NETÒ (80).

Cuidar, julgar - ME (74).

Cuieté - PREBÙ (17).

Culpa, por - AMEPRÈ (20).

Cunhado - UWÒ (22). 
Curto - MÙ, MUNETÈ (53).

Cuspo - EICÙ (21).

\section{D}

Dacolá, daí - BOROHÒ, BOURÒ (92).

Dádiva - UBÀ (61).

Dado, ser - DI (25).

Daí - IBÒ (92).

Dantes - TUDENHÈ (93).

Daquem - CATCIHÒ (92).

Daqui - BOIGÜ (91).

Daqui a pouco - BÜDIRÒ (88), MORÈ, MORECÙ (93).

Daqui em diante - DO IGÜDI (92).

Dar - DI (85).

De - NÒ (19).

De (Lat. EX) - BÒ $(19,85)$.

De (necessitar) - AIBÜ $(20,84)$.

Debaixo (prep.) - BENDÒ, WONHEHÈ $(85,87)$.

Debaixo (adv.) - RADAMÜ (93).

Deitado, estar - BAPI (67).

Deixar - PRI (70).

Demasiadamente - CRUBÜ (91).

Dente - DZÀ (15).

Dentro - RADAMÜ (93).

Depressa - CANANEKIÈ (92).

De repente - BEIPRI (89).

Desagradar-se - EDÈ $(28,79)$.

Descansar - EICÒ $(31,32)$.

Descer - CRARAIDYÒ (28). 
Descer abaixo - TÜ (29).

Desejar - NEYENTÀ $(29,80)$.

Desejar fumo - TANÈ (29).

Desejo de comer carne, ter - EIBARÙ (28).

Desonesto - PONHÈ (17).

Deslocar-se - DAPRÒ (33).

Desmentir-se - TOPRÒ (34).

Desposar-se - USARUNGUWONHÈ (81).

Desta maneira - MORI, MORINE (88).

Desviar-se das flechas - CAHÀ (28), BÜRIRIPI (32).

Detrás das costas (Lat. A TERGO) - WOROMÜ (93).

Deus - TUPÃ $(4,6)$

Devagar - HEHÈ (89).

Dez - MÜCRIBAE MISÃ SAÍ (6).

Dia, de - CAYAPRI (92).

Diligente - KEITENÈ (23).

Dinheiro - TAYÙ (24).

Direita, lado direito - BOROWONHÈ (76).

Direitamente - HONÈ (90).

Distante - MANI (33).

Dizem, contam - -DE, -DÈ $(73,95)$.

Dizer - MÈ (73), KENDÈ (98).

Doente - CANGHIKIÈ (66).

Doer - UNÙ (80).

Doido, ser - WONGHECRI (29).

Dois - WACHÁNI (6).

Donde - BOMODÈ (88).

Dono da casa - DERARI (82).

Dormir - UNÙ $(56,66)$.

Duro - TÇÃ (53). 
E

E (Lat. QUE) - BÆ (97).

E, também - DEHE ${ }^{\mathrm{n}}$, NO DEHE ${ }^{\mathrm{n}}$, NODE (97).

Eia! (Lat AGE, AGEDUM, sollicitantis; voz de homem) - YÀ (97).

Eis - NE (90).

Eis aqui - MOIGÜNÈ (93).

Ele, ela - I, S-, SE, SI, SU (11), IGÜ (90).

Eles, elas - I...A, S...A, SE...A, SI...A, SU...A (11).

Em - MÒ (86).

Em cima - YEMÜ (92).

Emagrecer - CRATCEWI (28).

Embarrar - TIDIÈ (34).

Embebedar-se - WODÒ (30).

Embira, corda - DZITÙ (23).

Embrulhar-se o estômago - MÜDÈ (28).

Encarnado - CUTÇÚ (53).

Encobrir - KEICÒ $(35,79)$.

Encontrar - DÈ $(28,80)$, IDJÈ (80).

Encurvar-se - DATÒ (33).

Endoidecer - WONGHECRI (29).

Enfadar-se - BAHÈ $(27,81)$.

Enfastiar-se - YACÒ $(28,79)$.

Enganar-se - UKEMBI (79).

Engatinhar - PEBAWITCETÒ (33).

Engenho de moer - WIRAPARARÁ (25).

Enojo, ter - BIDZONCRADÀ (27).

Enquanto - CODORÒ, SORÒ (88).

Ensinado, ser - BOHÈ $(30,81)$. 
Então - DORÒ $(36,88)$, DOCOHÒ, COHÒ $(36,91)$.

Entrar - DIÒ, IDIÒ $(28,67)$.

Entrepor-se a alguma coisa - SUDÀ (81).

Entristecer - DZEYÀ (28),

Enxada - TASI $(24,97)$.

Enxurrar - PEHÒ (29).

Erguer-se - BÆIWİ (32).

Errado do caminho, andar - WONGHEBÜ (81).

Escasso - EICORÈ (23).

Escada - BABÆCHÈ, BEBETÈ (13).

Escapar, escapar fugindo - NHEDÈ $(29,81)$.

Esconder-se atrás de uma moita - WANHIDÒ (29).

Escondidas, às - BENDÒ (89).

Escorregar - HEHÈ (33).

Escravo - BORONUNÙ (22).

Escuras, às - SINEKIÈ (93).

Espancado, ser - PO (90).

Espelho - WARUÀ (18).

Esperando, ficar - TODI (77).

Esperar - BABANHI (27),

Espeto - BABASITÈ (22).

Espia - WOROYÀ (25).

Espiga - BU (14).

Espingarda - SADÀ (17).

Espirrar - ERENTI (31).

Espora - YARIDZI (23).

Esposa, uxor - IDEINÙ (51).

Esquecer, ser esquecido de alguém - NABETCÈ $(28,81)$.

Esquerdo - WASÙ (18).

Esse - ERÒ (9). // Esses - ERÓÁ (9). 
Estalar - SADÀ (33).

Estar - BÀ, Pİ (32, 33). // Está aí - PIDE (95). // Estão aí - BADE (95).

Estar em campo contra ou em presença de alguém - TODI (80).

Estar no chão - DAHI (33).

Este - ERÍ, IGHÍ. // Estes - ERIDZÀ (9).

Este, esse, isto - COHÒ (9).

Estrepar-se - TÇAHÒ (34).

Eu - HIETÇÃ (7); HI, HIDZ-, DZU (11); TÇÃ, em: YACÀ WÒ TÇÃ? - Sou por ventura um cão? (96), TETÇÃ BO HIBÜSAPRI - Vim para que não me açoitem (71).

Explicado, ser - BENHÈ (80).

Estendido ao sol ou ao fogo, ser - BANHÈ (80).

\section{F}

Faca - UDZÀ (99).

Falar - MÈ (33).

Faltar - WAKIÈ (29).

Fanhoso - NHECARÀ (16).

Farinha de milho fresco - MAIRÙ (24).

Fartar-se - BUHÒ (28).

Favor, ter - BE (27).

Fazenda - WANHERÈ $(18,94)$.

Fazendo, estar - ITÙ (46).

Fazer-se - NIÒ (76).

Fazer-se (Lat. EVADERE) - WI (79).

Fedorento - COHÈ (14).

Feijão - GHINHÈ (60).

Feito, ser - MORÒ (30).

Fel - TCIHÈ (18). 
Fêmea - TIDZI $(55,98)$.

Ferro - MERATÀ (16).

Ferrugento - KÜDICÙ (94).

Ficar esperando - TODI (77).

Fígado - PRENHÈ (17).

Filho - INHURÆ $(1,6)$, NHÙ, NÙ (51).

Fino - KEMPÈ $(2,53)$.

Fio - HÒ (16).

Fita - MÜMÜCÀ (24).

Flecha - BUICÙ (22).

Flor - PURÚ (17).

Fogaça - POBEBÀ (24).

Fogagem - CÓ (21).

Fogo - ISÙ, SÙ (25).

Fogo, instrumento de tirar - NHÙPÜTÈ (24).

Foice - CREYAHÈ (23).

Folgar - ERACHICHI $(31,73)$.

Folha - ÆRÃ (20).

Fonte - EBEDZÙ (16).

Forno - BUBE ${ }^{\mathrm{n}} \mathrm{HO}(22)$.

Frequentemente - YÒ (90).

Frio - CUNHI (66).

Fruta - SUTÙ (53).

Frutas colhidas verdes para amadurar em casa - UBÒ (60).

Fumegar - PUIPÙ (33).

Fumo - BADZÈ (13).

Furtar - COTÒ (28).

Fuso - BURUHÙ (23).

G 
Gadelhas - BEDZERI (13).

Galinha - SABUCÀ (61).

Gancho - YAWÒ (23).

Garganta, osso da - KIBÙ (23).

Gemer - MUDUCHİ (28).

Genipapo - ME (16).

Genro - MÜTÈ (24).

Gente - TÇÕHÒ (18).

Girau para moquém - MEREBÀ(24).

Gordura - SÀ (17).

Gostoso - ITÀ (57).

Graça, de (Gratuito) - YEWÒ (90), COHÒ (89).

Grande - YE ${ }^{\mathrm{n}}$ (53); YACHI: DICRI UDZÀ YACHI - deu-se a faca grande (99).

Grosso - TÙ (53).

Guarda no caminho - DENHÈ (15).

Guardada, coisa - NECÀ (16).

Guardar-se - ENUNHÈ (32).

Guerra - CROPOBÒ (15).

Guerrear - CROPOBÒ (32), MARIDZÀ (35).

Guindar-se - SEMÜMÜ (35).

Guirajao (?) - BUDUDÙ (22).

\section{H}

Há muito tempo - KENHÈ (93).

Há pouco - DO IGÜDZÃ (92).

Haver - TÇOHÒ (29).

Haver mister - EICÒ (35).

Hoje - DO IGÜ (92). 
Hoje, pelo tempo que já passou - MINEHE ${ }^{\mathrm{n}}$ (93).

Homem, gente - TÇÕHÒ (18).

Homem, macho - ERÆ $(52,98)$.

I

Igreja - ERÀ TUPÃ (57).

Ilharga - TEHATÈ (18).

Impacientar-se - CUHÈ $(23,80)$.

Importunamente - TÒ (91).

Índio (s) - NHIHÒ (63).

Inimigo - MARÃ (24).

Instrumento de boca - BADÀ (22).

Instrumento de tanger - WARARÀ (18).

Inteligivelmente - WORONÈ (91).

Interpretar - WORONÈ (79).

Intérprete - WORONE (19).

Ir - WI (29, 34), BÜ (74).

Ir em busca de alguém - BÜ (80).

Irmã mais moça - BÜKÈ (14).

Irmã mais velha - DZEDZÈ (15).

Irmão mais moço - BÜRÆ (14).

Irmão mais velho - POPÒ (17).

Isso - URÒ (9).

Isto - COHÒ (9).

J

Já - CRI (89).

Já disse - BERÒ (91). 
Jeito, maneira - IWÒ (74).

Jejuar - WAWÃDÀ (29).

Joelho - CUDÙ (15).

Juntas do corpo - ECUDÙ (21).

Junto (Lat. APUD) - AMÜ (34).

\section{$\mathbf{L}$}

Lá - MOROHÒ (93).

Lado direito - BOROWONHÈ (76).

Ladrão - DICOTORI (52).

Ladrar - ENCÙ (33).

Lágrimas - IPOCÙ (51).

Lançar cheiro - ANDI (31).

Lavoura - UANHI (60).

Legume - UDJÉ (60).

Lembrado, ser - NHENETİ (30).

Lembrar-se de coisa necessária - NETÒ, NETONGHI (29).

Lenha - ISÙ, SÙ (25).

Levado, ser - BÜPI (30), MÜ (25).

Levado recado aos ausentes, ser - MÜNHEDÀ (80).

Levantar-se, e ir-se - TIHIWI (34).

Levantar falso, aleive - MEPEDİ $(35,79)$.

Levar - MÜ (89).

Levemente - HEHÈ (89).

Lhe, para ele - IDIOHÒ $(9,85)$.

Lhes, para eles - IDIOHOÀ (85).

Licor - CU (15).

Licor, denso - CROTÈ (15).

Limpo - KENKÈ (53). 
Língua - NUNÙ (17).

Livro, carta - TORARÃ (25).

Logo - BÜDIRÒ (88), IGÜDZÃ, (92), MORÈ, MORECÙ (93).

Longe - DAMÀ (92).

Longe, de - DINHI (89).

Lutar - TEUDIOKIÈ (34).

Luz - BUHÈ (95).

M

Machado - BODZÒ $(14,57)$.

Macho - RÆ (17), ERÆ (98).

Maduro - CHEDÈ (53).

Mãe - DE (15).

Mais - MÆHÆ (90).

Maldade - BUANGHETÈ $(52,75)$.

Mandioca - MUICÙ (60).

Mandioca assada, bolo de - WARUDÙ (25).

Mangaba - UCRI (60).

Manhã - CAYE ${ }^{n}$ (14).

Manquejar - PETÒ (33).

Mansamente - HEHÈ (89).

Mantimento - AMI (66).

Mão - MÜSÃ. (20). Nos numerais vem MISÃ (6).

Marapirão - CRENÙ (23).

Marca de ferro - TOCRAÙ (24).

Marido - RENGHÈ (24).

Mas - NERÙ (98).

Mastigar - NHÙ (33).

Matalotagem - ECODÒ (21). 
Matéria - SANÈ (17).

Mato - IRETCÈ (51).

Mato, borda de - BENETÈ (14).

Mau - BUÂNGHE (52).

Me, a mim - HIDIOHÒ $(7,85)$.

Medo, por (prep.) - DEZENÈ (19), DZENÈ (85).

Medonho, ser medonho - POTÙ $(17,80)$.

Medroso - BANARECÙ (94).

Mel - KENTI (59).

Menino - NHÙ (17), UINÙ (78).

Mentir - UPRE (79).

Mentiroso - PRETORÈ (14).

Mesinha - DZÒ (15), WARANDZI (25).

Mestre - DUBOHERI (50).

Meu - HIETÇÃ (11), HI, HIDZ-, DZU (11).

Migalhas, em - PEIPÈ, PEPÈ (90).

Milho - MASICHI (50).

Milho assado - MADZÒ (16).

Milho cozido - CRONHAHÀ (23).

Milho, pendão do - SOMBÜ (18).

Milho, vinho de - NHUPÜ (24).

Miolos - TCETÀ (18).

Moída, coisa - TÇÀ (24).

Molhar-se a roupa - CURÆMPÀ (28).

Montão - NERÙ (95).

Monte mor de coisas comestíveis - SANHICRÃ (24).

Moquém - BADZURÙ (13).

Moquém, jirau para - MEREBÀ (24).

Morada - BATÈ $(12,21)$.

Morador da casa - DERARİ: (52). 
Morder - SÕ ou Õ? Na frase: NO HIWI MO BECHE ${ }^{n}$ SÕ HIETÇÃ NO WÒ indo para a roça me mordeu uma cobra (74), Talvez - ser mordido. SÕ ou Õ? Note-se que não há palavras principiadas por $\mathrm{O}$.

Morrer - NHÀ (29).

Morto, ser - PÀ $(32,45)$.

Mostrado com a mão, ser - TOBÀ (80).

Mudar-se de lugar - NEMBÆ (81).

Muitas vezes - YÒ (90), TÒ (91).

Muito - CRUBÜ $(58,91)$.

Muitos - BUYÒ (6, 14), TÇOHÒ (6), YÒ (53).

Mulher - TIDZI $(6,95)$.

$\mathbf{N}$

Nadar - PONHÙ (29), BAHÀ (32).

Não (Lat. NON) - CO (89), DÜ, KIÈ (90).

Não (Lat. NEQUAQUAM) - COHODÜ (88).

Não (Lat. NE, adverbium vetandi) - NORI...NÈ, RI...NÈ (88).

Não há - WANDÜ $(73,91,95)$.

Não é possível (Lat. NULLATENUS) - HOMOTẼ (92).

Naquela parte (Lat. ILLIC) - DEHE ${ }^{\mathrm{n} T C I}$ (92).

Nariz - NÆMBI (16).

Nascer - SÀ (33).

Necessário, ser - NETONGHI (80).

Necessitar - EICÒ (35).

Negro (homem) - TAPANHÙ (56), GORÀ (100).

Neta - TEKÈ (18).

Neto - TE (18).

Nódoa - DIMÜ (grafado DIMỸ, com til) (21).

Noite - CAYÀ (3). 
Noite, alta - CAYADÈ (92).

Noite, à boca da - KIERETÙ (93).

Nojo, ter - BIDZONCRADÀ (27).

Nome - DZÈ (15).

Nomeado, ser - PERETÒ (80).

Nós (excl.) - HIETÇÃDE, HI...DE, HIDZ...DE, DZU...DE (7, 11).

Nós (incl.) - KETÇÃ, KETÇÃA, CU, CU...A, K...A $(7,11)$.

Nos, a nós outros - HIDIOHODE (7).

Nos, a nós todos - CUDOHÒ (7).

Nosso (excl.) - HIETÇÃDE, HI...DE, HIDZ...DE, DZU...DE $(7,11)$.

Nosso (incl.) - KETÇÃ, KETÇÃA, CU, CU...A, K...A (7, 11).

Notícia - EINHÈ (20).

Novamente, de novo - CHÈ (89).

Novas- WOROBÜ (25).

Nove - MÜREPRÍ SUMARÃ ORÓBÆ (MISA) SAÍ (6). Foi omitida a palavra MISÃ por Mamiani.

$\mathrm{Nu}$ - CRONÉ (15).

$\mathbf{O}$

O’! (vocat.) - BÒ! (88).

O'! (Lat. PAPE, VAH, admirantis) CUHÈ (96).

O’! (idem, voz de mulher) - HOHÒ (96).

Olhar - NÈ $(33,80)$.

Olhar pasmado - BIDZORÀ, BIDZORATÒ (35).

Olho - PÒ $(17,51)$.

Olhos, menina dos - ICOPÒ (51).

Ombro - NEBARÙ (16).

Ontem - CAYAHÒ (92).

Opilação - MUTÈ (16). 
Ora-sus! - MEHI! (97).

Orelha - BENHÈ (14).

Ornato de penas - BADİ (22).

Osso - ME (16).

Osso da garganta - KIBÙ (23).

Ótimo - CANGHIIDZÃ BÒ HOHOCRIBÆ; CANGHIWIDÓBÆ (58).

$\mathrm{Ou}$ - BOHÒ (97).

Outeiro - BENDÒ (86).

Oxalá - PROH (91).

$\mathbf{P}$

Padre - WARÈ $(3,57)$.

Paga - AMBÈ (19).

Pai - PADZÙ $(13,17)$.

Palheta de jugar - BÜBÜTÈ (22).

Paliçada - MÆNÀ (16).

Panela - RUNHÙ (17).

Pano - CRUTÈ (15).

Panos velhos - ANDZÈ (22).

Papas - BUREHÈ (23).

Para (dativo) - DÒ (85).

Para, contra - Aİ, AMÜ, MÜ, SÒ $(20,84,86,87)$.

Para cá - CATCIHÒ (92).

Para lá, para a outra parte - CATCI (92).

Para onde? Aonde? - MODÈ? (88)

Para que? - IDIOHODE? (88).

Para que (conj.) - BÒ (98).

Para que não - BÒ (98).

Páreas - MAIBÀ (23). 
Parente - ETSAMÜ (20).

Pazes, fazer - INHÆHI (80).

Passar o rio - MÜBÀ (28).

Passear - TUYOKIÈ (29).

Pau, tronco de - HEBARÙ (16).

Pé - BÜ $(14,51)$.

Pé, palma do - PEPETÈ (17).

Pecado- BUÂNGHETÈ $(14,75,77)$.

Pedir - CRIKIÈ $(28,56,79)$.

Pedra - CRÒ (23).

Pegar - TA (91).

Pegar-se - BABÆ (81).

Peito - CRABÙ (15).

Peixe - MÜDZÈ (57).

Pejo, ter - ARANCRÈ (31).

Pela de jogar - PEPÈ (24).

Pelejar - MARÃ (79).

Penas novas - SONGÀ (18).

Peneira - KÜHIKI (23).

Pente - BAKIRIBÙ (13).

Pequeno - PI, PINETÈ (53).

Perfeitamente - WONHÈ (91).

Perguntar - EREKIDİ $(35,79)$.

Perna - WÕ (18).

Perna, canela da - EBEYÀ (16).

Perto - DAMAKIÈ (92).

Perto, de; chegado - DEDI, DIDI, DEDÈ (89).

Pescoço - NE (16), HONÆ (55).

Péssimo - BURÈ CRUBÜ BÒ HOHOCRIBÆ (mau sobre tudo) (58).

Petição, coisa pedida - ICRIKIÉTÈ (83). 
Piolho - DÙ (15).

Pisada, coisa - DATÙ (23), TÇÀ (24).

Pisar - PÈ (33).

Planta (vegetal) - UBUMANÀ $(51,76)$.

Pluralização, sufixo de - TÈ $(6,95)$.

Pó que fica da farinha - CUNUBÒ (23).

Pobre - WONGHERÈ (18).

Poder - NÙ (46).

Polpa - TÙ (18).

Ponta - TÇONCÀ (18).

Por (prep. - de espera) - BÃBÙ, BAMBÙ, BETÈ $(19,85)$.

Por (Lat. PROPTER - de causa) - NÒ (86).

Por, para, em (AD, SUPER) - MÒ (86).

Por amor - (Lat. PROPTER) - BÒ (85).

Por causa - NO $(19,86)$.

Porco - MURAWÒ $(51,60)$.

Por culpa - AMEPRÈ (20).

Por isso - INARÒ $(89,98)$.

Por medo, respeito, vergonha - DEZENÈ (19), DZENÈ (85).

Por que? - SÒDE? (88).

Porque (conj.) - NÒ, NORI (98).

Pouco - RERÈ (90).

Praticar - TÙ $(29,81,82)$.

Prato - ARIBÀ $(20,50)$.

Prato para fazer louça - WERETÈ (25).

Pregado, estar - BADİ (81).

Pregão, ser botado - WATCÈ (80).

Preguiça, ter - NHICORÒ (29).

Preparar-se, ser preparado - TÒ (77).

Presa (coisa apresada) - BORONUNÙ $(22,60)$. 
Presença, em - PENEHÒ $(19,87)$.

Preto - COTÇÒ (53).

Priaca frecha (?) - YARÙ (16).

Primeiro - BIHE (6), KIEHÒ (Lat. PRIUS TEMPORE) (90).

Primogênito - DISAKIÈHORI (90).

Principal da casa (pessoa) - ISE (6).

Propósito, de (adv.) - COHÒ, HÒ $(89,90)$.

Próximo - ETSÕHÒ (20).

Pulso - ENÆ (21).

Q

Qual (Lat. QUI, NULLATENUS) HOMOTÈ (92).

Quando - INGHI (90).

Quando? - UDJEINGHI? (93).

Quantas vezes? (Lat. QUOTIES?) - SODEYÒ (88).

Quatro - SUMARÃ ORÓBæ (6).

Que? - UDJE? SODÈ? -DE? -DÈ? $(56,57)$.

Quebrado, quebrar - BÜSÀ $(66,95)$.

Quebrar-se - BÜNÈ, BÜPÈ (32).

Quebrar-se em pedaços - PEDÀ (94).

Queimar-se o corpo - CONGÒ (28).

Quem? - ADJE? -DÈ? -DE? $(3,56,57)$.

Querer - SÆRÆ (46).

Quinhão - WANHUBATÇÃ $(18,60)$.

$\mathbf{R}$

Rabo - CRÙ (15).

Raiz - MU (16). 
Ralo de ralar - ERÙ (23).

Rasgar-se - SACRÈ (29).

Rastejar - UPEBAWI (79).

Rasto - EWÕ (20).

Recente - BARÆ (89).

Reconhecer - UBETE (79).

Recordar consigo - UPEBAWI (79).

Rede - PITÈ $(17,85)$.

Rede de pescar - MUHÈ (16).

Redondo - TÒ, TOTÒ (53).

Relâmpago - TIDZEHEHOBÒ (18).

Reluzente - DZODZÒ (53).

Repartição, quinhão - UKICI, WANHUBATÇÃ (60).

Repartir - UNÀ (79).

Repousar - DABÀ (32).

Resgate, resgatar - NHÆHI $(16,79)$.

Ressurgir - IBUÒ (28).

Rever o licor - BÜDZÙ (28).

Revés, de - WIPOKIÈ (93).

Rijamente - TÇÃ (91).

Rio - IWO. Na frase: PEHÒ IWODZÙ MO IMERÀ - correu a água do rio pelos campos (76).

Robusto, ficar robusto - CRODI $(15,75)$.

Rir - HÆHÆ (28).

Roça - BECHIE ${ }^{\mathrm{n}}, \operatorname{BECHE}^{\mathrm{n}}(47,73,74)$.

Roca de fiar - POPONGHI (24).

Rodear o mato buscando caça - BÜRÒ (35).

Roncar - CRARÁUNÙ (72). 
Saber fazer - UNÈ (79).

Sabido, ser - NETÇÒ (30).

Saboroso, ser - ITÀ (80).

Saia de pindoba - SASÀ (24).

Saltar - SAIPRÌ (33).

Sangue - PRI (17).

Sarar - EICÒ (32).

Saudades, ter - NHANHIKIÈ (29).

Se (conj.) - NÒ (88).

Sebo - ISÀ (5).

Secar - SADÀ (33).

Secar-se a raiz - POHÀ (33).

Seco - CROCRÀ (15), CRÀ (53).

Seço (?) - WOYÈ (18).

Segundo - WACHÁNI (6).

Seis - MÜREPRÍ BUBIHÉ MISÃ SAÍ (6).

Seja assim, embora (Lat. BENE EST) - HOMODI (92).

Sem causa, sem motivo - IDZÃDZÃ (90).

Sempre - IDADÈ (90).

Senhor, amo - SE $(17,65)$.

Sepultura - BUDEWÒ (14).

Serra (instr.) - SIRIRITÈ (52).

Serrar - RI (52).

Sete - MÜREPRÍ WACHÁNI MISÃ SAÍ (6).

Seu (dele, a) - I, SE, SI, SU, S- (11).

Seu (deles, as) - I...A, S...A, SE...A, SI...A, SU...A (11).

Sim - COHÒ (88).

Simplesmente, sem mistura - IDZÃ (90).

Sinal no corpo - MECÀ (24). 
Sob - BENDÒ (85), WONHEHẼ (87).

Sobre tudo, mais que tudo (Para formar o superlativo) - WIDÒ, WIDÓBÆ; BÒ HOHOCRIBÆ (58). V. "ótimo" e "péssimo".

Sobrinha - BÆKÈ (13), YÆHÈ (16), TENHÀ (18).

Sobrinho - DZÕ (15), NHUANHÀ (17), TE (18).

Sogro - DZACÀ (15).

Solteiro, viver - ENEWI (28).

Somente - BIHÈ (88), WOIBIHO (93).

Sonhar - UNÆ $(74,81)$.

Subir - IBÆ (33).

Sucessor - SINHÃ (17).

Suor - BUNHICÒ (14).

$\mathbf{T}$

Talvez, por ventura - CUNÈ, KIDÈ (91).

Talvez que seja assim - HOMOROKIDÈ (92).

Também - DEHEn ${ }^{\mathrm{n}}$, NO DEHE ${ }^{\mathrm{n}}$, NODE (97).

Tapuias bravos - WOYÊN (4).

Taquara - YÆNTÀ (16).

Te, a ti - EDOHÒ (85).

Tear - WONCURÒ (25).

Temer - BANARÈ (27).

Tempos passados, nos - TUDENHÈ (93).

Ter mister - UWANHI (79), EICÒ (82).

Terceiro - WACHÁNIDIKIÈ (6).

Tesamente - TÇÃ (91).

Testa - COBÈ (14).

Testículos - SONDÈ (18).

Teta - MAMÀ (16). 
Teu - EWATÇÃ (9), E, EY-, EDZ-, A (11).

Tia - ANHÀ (13)' DEDENHÈ (15).

Tio - PAIDENHÈ, PAYE $^{n}$ (17), CUCÙ (15).

Tirai lá! (Lat. APAGE; voz de mulher) - AMÙ! (96).

Tocaia - AMBÙ (19).

Todos - CRIBÆ, CRIBUNÈ, WOHOYE ${ }^{\mathrm{n}}(6,52)$.

Todos sem exceção - BÒ (94).

Tomar - MÜ (70).

Tornar depressa - PEHÈ (29).

Torrão - CRÆRÙ (15).

Totalmente - ÆMPRI, PRIBÆ (88); IDZÃ (90).

Toutiço - CONECÀ (14).

Trabalhar - NATÈ (28), NA (77).

Transanteontem - CAYAHOHÒ (92).

Transbordar o que ferve - SEBÒ (33).

Transbordar o rio - SEWİ (34).

Traque - BICÒ (14).

Tratar com alguém de alguma coisa - NUSI (80).

Trazer - MÜTÈ (73).

Tremer - TITİ (29).

Três - WACHÁNIDIKIÈ $(6,53)$.

Tripas - HÈ (16).

Triste - BESİ (14).

Tronco - BEWÕ (14).

Tronco de pau - HEBARÙ (16).

Tu - EVIATÇÃ, E, EY-, EDZ-, A $(9,11)$.

$\mathbf{U}$

Ui! (Lat. HUI, admirantis) - YUH!, YUHYÀ! YUHYÀRETÈ! (97). 
Um - BIHÈ (6).

Umbigo - MUCRI (16).

Unha - EBAYÀ (21).

Urina - SONCÒ (18).

Urucu - BUCRENKÈ (14).

Uxor, esposa - IDEINÙ (= mãe de seus filhos, portanto: sua esposa; m. esposa - IDEHINÙ, t. esposa - IDEENÙ, etc.) (51).

V

Vaca - CRADZÒ (5).

Varge - PÔHÔ (17).

Veado - BUKE (60).

Veia - CADAMÜSİ (14).

Velha (mulher) - RUTÈ (24).

Velho - RENGHE (graf. RHENGE) (2).

Ver - NETÇÒ (69), UBI (79).

Ver com admiração - WOROYENTÀ (79).

Verdade, na - SAMBÜYÈ (93).

Verdadeiramente - IDZÃ (90).

Verde - ERÃ (53).

Vergonhoso - ARANCRERÙ (95).

Virilha - ECRIDZÃ (20).

Vermelho - HÈ (53).

Vestido, roupa - RÒ $(17,52,60)$.

Vezes, às - HEHÈ (89).

Vigário - ISINHÃ (66).

Vinho de milho - NHUPÜ (24).

Vinte - MÜCRIBÆ MISÃ IDEHÒ IBÜ SAÍ (6).

Vir - TÈ, TE $(29,46)$. 
Vir depressa - BROCÀ (97).

Virar-se para ver - BEINÈ (27).

Viril, membro - NHE (16).

Virote - COTÒ (15).

Visitar - ERIWI (28).

Vista, à - PENEHÒ (87).

Visto, ser - NETÇÒ (89).

Voar - HÒ (33).

Vontade, ter - NHICRÆ $(29,79)$.

Vontade, não ter - NHICORÒ (79).

Vos, a vós- EDOHOÀ (85).

Vós, vosso - EWATÇÃA, E...A, EDZ...A, A...A $(9,11)$.

Z

Zombar - UTÇOTÇOHÒ (79), TUYÒ (80).

\section{KIRIRÍ-PORTUGUÊS}

A - Tu, teu (11); a gente (= MIRA do tupí, ON do francês, MAN do alemão, etc.) (94); designativo de plural, usado com nomes de coisas que pertencem à gente $(6,94)$.

A...A - Vós, vosso (11).

ADJÈ, ADJE - Caça $(83,100)$; quem? $(3,56,99)$.

ÆMBURÈ - Apressar-se (27).

ÆMPRI - Totalmente (88).

ÆRÃ - Folha (20). 
AGÀ, AGANORI - Ai (Lat. HEU, dolentis; voz de mulher) (96).

Aİ - A, para, contra $(20,84)$.

AIBÜ - De (usada somente com o verbo necessitar) $(20,84)$.

AMBÈ - Paga (19).

AMBÙ - Tocaia (19).

AMEPRE - Por culpa (20).

AMİ - Comida, mantimento $(20,66)$.

AMPRİ - Fronteiro (20).

AMÚ - Tirai lá! (Lat. APAGE, execrantis; voz de mulher) (97).

AMÜ -Para, com (Lat. APUD, VERSUS - com pessoa) $(20,84)$.

ANDI - Lançar cheiro (31).

ANDZÈ - Panos velhos (22).

ANHÀ - Tia (13).

ANHI - Alma (19).

ARANCRÈ - Ter pejo (31).

ARANCRERÙ - Vergonhoso (95).

ARÍ - Arrelá! (Lat. APAGE, execrantis; voz de homem) (96).

ARIBÀ - Prato $(20,50)$.

AWİ - Agulha (22).

B

BÀ - Estar (32). // BADE - Estão aí (95).

BABÆ - Pegar-se (81).

BABÆCHÈ - Escada (13).

BABANHI - Esperar (27).

BABASITÈ - Espeto (22).

BÃBÙ, BAMBÙ - Por (prep., de espera) (19).

BACOBÀ - Banana $(13,60)$.

BADÀ - Instrumento de boca (22). 
BADI - Estar pregado, grudado (81).

BADİ - Ornato de penas (22).

BADZÈ - Fumo (13).

BADZURÙ - Moquém (13).

BÆ - E (Lat. QUE) (97); "partícula que serve de elegância no fim dos verbos, no indicativo, em particular se forem negativos" (94).

BÆIWI - Chegar com a mão (27).

BÆIWİ - Erguer-se (32).

BÆKÈ - Sobrinha (13).

BÆRÙ - Calcanhar (13).

BÆTÒ - Bordão (13).

BÆWI - Chegar com o corpo (80).

BAHÀ - Nadar (32).

BAHÈ - Enfadar-se $(27,81)$.

BAKIRIBÙ - Pente (13).

BANARÈ - Temer (27).

BANARECÙ - Medroso (94).

BANHE - Ser estendido ao sol ou ao fogo (80).

BAPI - Estar deitado (67).

BARÀ - Balaio (22).

BARÆ - De fresco, recém (89).

BATÈ - Morada (21).

BAYASİ - Assobiar (35).

BE - Beira (13).

$\mathrm{BE}$ - Ter favor (27).

BEBÀ - Colar de osso (22); afeiçoar a testa da criança (35).

BEBÀ, BEBATẼ - Fontes da cabeça (13).

BEBETÈ - Escada (13).

$\mathrm{BECHIE}^{\mathrm{n}}, \mathrm{BECHE}^{\mathrm{n}}-$ Roça $(47,73,74)$.

BEDZÈ - Cabo de instrumento (13) 
BEDZERI - Gadelhas (13).

BEHÈ, BEHETÈ - Chaga (13).

BEINE - Virar-se para ver (27).

BEIPRI - De súbito, de repente (89).

BENÃ - Caco (13).

BENDÒ - Debaixo (85); às escondidas (89).

BENDÒ - Outeiro (86).

BENETÊ - Borda de mato (14).

BENHÈ - Orelha (14).

BENHÈ - Ser contado (30); ser explicado (80).

BENHEKIE - Brincar (32).

BERÒ - Certamente, assim como digo, já disse (91).

BESİ - Triste (14).

BETÈ - Por (prep., de espera) $(19,85)$.

BETÈ - Chegar com o corpo $(27,80)$.

BEWÕ - Tronco (14).

BICÒ - Traque (14).

BIDZANCRÒ - Cara (14).

BIDZONCRÀ - Bocejar (27).

BIDZONCHADÀ - Ter nojo (27).

BIDZORÀ, BIDZORATÒ - Olhar pasmado (35).

BIHÈ - Um, primeiro $(6,53)$; somente $(88)$.

BIHÈ CRIBÆ - Cada um (6).

BÒ - Braço (14).

BÒ - De, por (Lat. EX, PROPTER) (19, 85); ó! do vocativo (88); inteiramente, sem exceção (94) ; para que, para que não (98).

BOCÒ - Algibeira (14).

BODZÒ - Machado $(14,57)$.

BOHÈ - Ser ensinado $(30,81)$.

BOHÒ - Ou (97). 
BÒ HOHOCRIBÆ - Sobre tudo, mais que tudo (58).

BOIGÜ - Daqui (91).

BOMODÈ - Donde (88).

BOROHÒ - Dacolá, daí (92).

BORONUNÙ - Escravo, presa (22,74).60).

BOROPÒ - Cotovelo (olho do braço) (52).

BOROWONHE - Lado direito, direita (76).

BOURÒ - Dacolá, daí (92).

BROCÀ - Vir depressa (97); apressa-te (46).

BU - Espiga (14).

BUÂNGHE - Mau (52).

BUÂNGHETÈ - Pecado, maldade (14, 52, 75).

BUBANGÀ - Rabisco de fruta (22).

BUBE ${ }^{\mathrm{n}} H O ̀$ - Forno, alguidar (22).

BUCRENKÈ - Urucu (14).

BUCÙ - Alvo (95).

BUCUNÙ - Capoeira, roçado velho (22).

BUCUPÜ - Flecha do milho (14).

BUCUTÈ - Cãs (14).

BUDEWÒ - Sepultura (14).

BUDUDÙ - Guirajao (?) (22).

BUHÈ - Luz (95).

BUHÒ - Fartar-se (28).

BUIBÙ - Cabaço (22).

BUICÙ - Flecha (22).

BUKE - Veado (60).

BUKERI - Agourar mal (35).

BUNHÀ - Barro (50, 76).

BUNHICÒ - Suor (14).

BUONHETÈ - Bondade (14). 
BURÈ - Mau, mal $(58,67)$.

BURÈ CRUBÜ BÒ HOHOCRIBÆ - Péssimo (mau sobre tudo) (58).

BUREHÈ - Papas (23).

BURÒ - Casca (14).

BURUHÙ - Fuso (23).

BUYE ${ }^{\mathrm{n}} W O H O ̀$ - Corpo (14).

BUYÒ - Muitos $(6,14)$.

BÜ - Pé $(14,51)$; correr (27); ir (74); ir em busca de alguém (80).

BÜBÜTÈ - Palheta de jogar (22).

BÜDI - Cinza (14).

BÜDIRÒ - Logo, daqui a pouco (88).

BÜDZÙ - Rever o licor (28).

BÜKÈ - Irmã mais moça (14).

BÜNÈ - Quebrar-se (32).

BÜPÈ - Quebrar-se (32).

BÜPI - Ser lembrado (30).

BÜPRÒ - Cair (32).

BÜRÆ - Irmão mais moço (14).

BÜRIRIPI - Desviar-se das flechas (32).

BÜRÒ - Barriga (22).

BÜRÒ - Rodear o mato buscando caça (35).

BÜSÀ - Quebrar (66); quebrado (95).

BÜSAPRİ - Açoitar $(63,64,71)$.

BÜTÈ - Tornar-se (32).

BÜTÒ - Fornicar (graf. BYTÒ nas duas páginas) $(28,79)$.

C

CÀ - Chamar por alguém (80).

CABARÙ - Cavalo (86). 
CADAMÜSİ - Veia (14).

CAHÀ - Desviar-se das flechas (28).

CANANEKIÈ - Depressa (92).

CANGHI - Bom, bem $(65,67)$.

CANGHIIDZÃ BÒ HOHOCRIBÆ - Ótimo (bom sobre tudo) (58).

CANGHIKIÈ - Doente (66).

CANGHITÈ - Obra boa (14).

CANGHIWIDÓBÆ - Ótimo (58).

CARAİ - Branco (homem) $(50,101)$.

CARATCÌ - Amanhã (92).

CATCI - Para lá, a outra parte (92).

CATCIHÒ - Para cá, da banda daquém (92).

CAYÀ, - Noite (3).

CAYADÈ - Alta noite (92).

CAYAHÒ - Ontem (92).

CAYAHOHÒ - Anteontem, transanteontem (92).

CAYAPRI - De dia (92).

$\mathrm{CAYE}^{\mathrm{n}}$ - Manhã (14).

CAYE ${ }^{\mathrm{n} O H O ̀ ~-~ D e p o i s ~ d e ~ a m a n h a ̃ ~(92) . ~}$

CHÈ - Novamente, de novo (89).

CHEDÈ - Maduro (53).

CHI - Comprido (53); até lá, não mais (Lat. USQUE) (89); "serve de elegância aos verbos e nomes de falar, gritar, perguntar" (94).

CÒ - Caroço (14, 51); fogagem (graf. CÓ) (21).

CO - Não (Lat. NON) (89).

COBÈ - Testa (14).

CODORÒ - Antes que, enquanto (88).

COHÈ - Fedorento (14).

COHÒ - Isto, este, esse (9); sim (Lat. ITA) (88); assim não mais, sem que nem para que, de propósito (89). 
COHODÜ - Não (Lat. NEQUAQUAM) (88).

CONECÀ - Toutiço (14).

CONGÒ - Queimar-se o corpo (28).

COTÇÒ - Preto (53).

COTÒ - Virote (15).

COTÒ - Comer que se guarda (23).

COTÒ - furtar (28).

CRÀ - Seco (53).

CRABÙ - Peito (15).

CRACÙ - Azul (53).

CRADZÒ - Boi, vaca (5, 7); carne (de vaca) (57).

CRÆ - Alfange (23).

CRÆERÙ - Torrão (15).

CRAMEMÙ - Caixa (15).

CRARAIDYÒ - Descer (28).

CRARAIWI - Correr o amarrilho (32).

CRARÁUNÙ - Roncar (72).

CRATCEWI - Emagrecer (28).

CRAYOTE - Cacimba (23).

CRENÙ - Marapirão (23).

CREYÀ - Assado em covas (23).

CREYAHÈ - Foice (23).

CRI - Já (89).

CRIBÆ, CRIBUNE - Todos (52).

CRIKIÈ - Pedir $(28,56,79)$.

CRÒ - Pedra (23).

CROBECÀ - Cuia (15).

CROCRÀ - Seco (15).

CRODI - Robusto (15); ficar robusto (75).

CRONÈ - Nu (15). 
CRONHAHÀ - Milho cozido (23).

CROPOBÒ - Guerra (15), guerrear (32).

CROTÇÃBÜ - Consolar-se (28).

CROTÈ - Denso licor (15).

CRÙ - Rabo (15).

CRUBÜ - Demasiadamente, muito $(58,91)$.

CRUDZÃ - Cofo (15).

CRUTÈ - Pano (15).

CU - Licor (15).

CÙ - Branco (53); no fim dos nomes adjetivos denota propriedade (94).

CU, CU...A - Nós, nosso (inclus.) (11).

CUCÙ - Tio (15).

CUDÙ - Joelho (15).

CUHÈ - Impacientar-se (28, 80); ó! (Lat. PAPE, VAH) (96).

CUNÈ - Por ventura, talvez (91).

CUNHI - Frio (66).

CUNUBÒ - Pó que fica da farinha (23).

CURÆMPÀ - Molhar-se a roupa (28).

CUROTÈ - Colher (subst.) (23).

CUTÇÙ - Encarnado (53).

\section{D}

DABÀ - Repousar (32).

DADAWI - Andar de cócoras (33).

DADI - Assentar-se (33).

DAHI - Estar no chão (33).

DAMÀ - Longe (92).

DAMAKIÈ - Perto (92).

DAMÜ- Carga aos ombros (23). 
DAPRÒ - Desfocar-se (33).

DATÒ - Encurvar-se (33).

DATÙ - Coisa pisada (23).

DE (átono) - "Se usa às vezes por elegância no fim dos verbos de estar, jazer, etc.: PIDE, está aí. Também denota grandeza, ou distância: NERÚDE grande montão. Também faz os nomes verbos; BUCÚDE - é alvo" (94).

DE - Mãe (15).

DÈ - Encontrar $(28,80)$; quem? que? $(56,57)$; diz, dizem: WANDÜDÈ - diz que não há $(73,95)$.

DEDENHÈ - Tia (15).

DEDI - Cerca de paus (23).

DEDI, DIDI, DEDÈ - De perto, chegado (89).

$\mathrm{DEHE}^{\mathrm{n}}-\mathrm{E}$, também (97).

DEHEBÀ - Cavador (15).

DEHEn $^{\mathrm{n}} \mathrm{TCI}$ - Acolá, naquela parte (92).

DEHÒ - Com (de companhia ou cúmplice) (85).

DENÃ - Coalhar-se (28).

DENHÈ - Guarda no caminho (15).

DERARİ - Morador da casa, dono da casa $(52,82)$.

DEZENÈ - Por medo (prep.) (19).

DI - Ser dado (25); dar (85).

DICANGHIRI - O que é bom, bom (subst.) (82).

DICOTORI - Ladrão (52).

DIMÜ - (graf. DIMY, com til no Y) - Nódoa (21).

DINHI - De longe (89).

DIÒ - Entrar (28).

DÒ - Acometer (80); a, para (dativo) (85); junto aos verbos dá a ideia de acabamento: NHUDOCRI - acabou de comer tudo (95).

DOCOHÒ - Então (36).

DO IGÜ - Hoje, agora (92).

DO IGÜCHI - Até agora (92). 
DO IGÜDI - Daqui em diante (92).

DO IGÜDZÃ - Inda agora, há pouco logo (92).

DORÒ - Então $(36,88)$.

DÙ - Piolho (15).

DUBÈ - Aio (15).

DUBOHERI - Mestre (50).

DÜ - Cabelo (15).

DÜ - Não (Lat. NON) (89).

DZÀ - Dente (15).

DZACÀ - Sogro (15).

DZÈ - Nome (15).

DZEDZÈ - Irmã mais velha (15).

DZENE - Por medo, respeito ou vergonha (prep.) (85).

DZEYÀ - Entristecer (28); afligir-se (77).

DZI - Cair (33).

DZIDÈ - Camerada mulher (15).

DZITÙ - Embira, corda (23).

DZÒ - Mesinha (15); chuva (76).

DZÕ - Sobrinho (15).

DZODZÒ - Reluzente (53).

DZÙ - Agua (15).

DZU - Eu, meu (11).

DZU...DE - Nós, nosso (11).

DZUWI - Ir-se embora (28).

E

E - Carga $(16,61)$.

EBAYÀ - Unha (21).

EBAYASİ - Assobiar (31). 
EBEDZÙ - Fonte (16).

EBEYÀ - Canela da perna (16).

ECODÒ - Matalotagem (21).

ECRIDZÃ - Virilha (20).

ECUDÙ - Juntas do corpo (21).

ECUWÕBUYE ${ }^{\mathrm{n}}$ - Céu superior (23).

EDÈ - Desagradar-se $(28,79)$.

EIBARÙ - Ter desejo de comer carne (28).

EICÒ - Sarar, descansar (32); haver, ter mister, necessitar $(35,82,84)$.

EICORÈ - Escasso (23).

EICÙ - Cuspo (21).

EINHÈ - Notícia (20).

EMBOHÒ - Com (de companhia) $(20,85)$.

ENÀ - Barba (21).

ENÆ - Pulso (21).

ENCÙ - Ladrar (33).

ENDI - Algodão (23).

ENÈ ENÈ - Exclamação de quem cai na coisa (97).

ENEWI - Viver solteiro (28).

ENKÈ - Chorar (33).

ENKI - Criação $(20,50)$.

ENUNHÈ - Guardar-se (32).

ERÃ - Verde, amarelo (53).

ERÀ - Casa (20).

ERÀ BUYE ${ }^{n}$ - Cidade (74).

ERACHICHI - Folgar $(31,73)$.

ERÆ - Homem (52), macho (98).

ERÀ TUPÃ - Igreja (57).

EREKIDİ - Perguntar $(35,79)$.

ERENTI - Espirrar (31). 
ERİ - Este (9). // ERIDZÀ - Estes (9).

ERIWI - Visitar (28).

ERÒ - Esse (9). // ERÓÁ - Esses (se se trata de gente) (9).

ERÙ - Ralo de ralar (23).

ETSAMÜ - Parente (20).

ETSÕHÒ - Próximo (20).

EWATÇÃ, E, EY-, EDZ- - Tu, teu $(7,11)$.

EWATÇÃA, E...A, EY...A, EDZ...A - Vós, vosso $(7,11)$.

EWÕ - Rasto (20).

EYABÀ - Espádua (21).

EYAPÒ - Crueiras da mandioca (23).

EYEMÈ - Balsa (21).

\section{G}

GHINHÈ - Feijão (60).

GORÀ - Negro (homem) (100).

GÜ - Ser cheirado (2).

$\mathbf{H}$

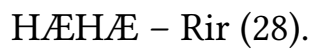

HÈ - Tripas (16); vermelho (53); ai! (Lat. AH, HEU, ingemiscentis) (96).

HEBARÙ - Tronco de pau (16).

HECHI - Alto (57).

HEHÈ - Escorregar (33); levemente, mansamente, devagar, às vezes, rara vez, pouco (89).

HENANDZİ - Cavaco (16).

HIETÇÃ, HI, HIDZ- - Eu, meu $(7,11)$.

HIETÇADE, HI...DE, HIDZ...DE - Nós, nosso (excl.) $(7,11)$. 
HÒ - De propósito (90).

HÒ - Fio (16).

HÒ - Voar (33).

HOHÒ - Ó! (voz de mulher; Lat. PAPE, VAH, admirantis) (96).

HOMO, HOMOBERÒ - Bofé, certamente (92).

HOMODI - Embora, seja assim (Lat. BENE EST) (92).

HOMODIRODI - Assim será, assim farei (92).

HOMONO? - Assim é? (92).

HOMÓRÒ - Ai! (Lat. HEU, miserentis) (97).

HOMOROKIDÈ - Talvez que seja assim (92).

HOMOTẼ - Não é possível! Qual! Será bom? (Lat. QUI, NULLATENUS) (92).

HONÆ - Pescoço (55).

HONE - Direitamente, a fio direito (90).

HÜ - Partícula que "se usa muito nas respostas, posta no fim da palavra, quando se responde com uma palavra só” (95).

I

I - Ele, ela, dele, dela (11).

I...A - Eles, elas, deles, delas (11).

IBÀ - Carro (23).

IBÆ - Subir (33).

IBÒ - Daí (Lat. INDE, ISTHINC) (92).

IBÓNÒ - Contudo (98).

IBUÒ - Ressurgir (28).

ICOPÒ - Menina dos olhos (51).

ICRIKIÊTÊ - Coisa pedida, petição (83).

ICÙ - Banquete (77).

IDABÀ - Arribar (33).

IDADÈ - Continuadamente, sempre (90). 
IDEINÙ - Sua esposa, uxor (mãe de seus filhos). Minha esposa - IDEHINÙ;

tua esposa - IDEENÙ (51).

IDIÒ - Entrar (67).

IDIOHODE? - Para que? (88).

IDJÈ - Encontrar (80).

IDZÃ - Verdadeiramente, totalmente, de todo, simplesmente, sem mistura (90).

IDZÃDZÃ - Sem causa, sem motivo (90).

IGHÍ - Este (9).

IGÜ - Ele (90). O mesmo que IGHÍ?

INARÒ - Por isso $(89,98)$.

INGHE - Criança $(2,23)$.

INGHI - Quando (90).

INHÆHI - Fazer pazes (80).

INHURÆ - Filho $(1,6)$.

INIÒ - Conserto de ferramenta (23); tornar a consertar (35).

IPABÒ - Confessar-se $(35,79)$.

IPOCÙ - Lágrimas (51).

IRETCÈ - Mato (51).

ISÀ - Sebo (5).

ISE - Principal da casa (6).

ISINHÃ - Vigário (66).

ISÙ - Fogo, lenha (25).

ITÀ - Gostoso (57); ser saboroso (80).

ITÙ - Começar ou estar fazendo (46); ser agradável (80).

IWÒ - Modo, jeito (74); rio (na frase: PEHÒ IWODZÙ MO IMERÀ - correu a água do rio pelos campos) (76).

IWODZÙ - Agua do rio (76).

$\mathbf{K}$ 
KEICÒ - Encobrir $(35,79)$.

KEITÈ - Jeito (23).

KEITENÈ- Diligente (23).

KEMPÈ - Fino $(2,53)$.

KENDÈ - Avisar (28, 79), dizer (98).

KENHÈ - Antigamente, há muito tempo (93).

KENKÈ - Alvo, limpo (53).

KENTI - Mel (59).

KETÇÃ - Tomar chamusco o comer (28).

KETÇÃ, KETÇÃA, K...A - Nós, nosso (inclus.) $(7,11)$.

KIBÙ - Osso da garganta (23).

KIDÈ - Por ventura, talvez (91).

KIÈ - Não (Lat. NON) (90).

KIECHI - Coma (subst.) (16).

KIEHÒ - Prius tempore (90).

KIERETÙ - À boca da noite (93).

KITCI - Areia (2).

KÜDI - Bolor (16).

KÜDICU் - Ferrugento (94).

KÜHIKI - Peneira (23).

M

MADZÒ - Milho assado (16).

MÆHÆ - Mais (Lat. ULTERIUS) (90).

MÆNÀ - Paliçada (16).

MAIBÀ - Páreas, clara de ovo, etc. (23).

MAIRÙ - Farinha de milho fresco (24).

MAMÀ - Teta (16).

MANDI - Com (de carga, cargo ou cuidado) $(20,86)$. 
MANI - Longe, distante (93).

MARÀ - Cantiga (20).

MARÃ - Inimigo (24); pelejar (79).

MARIDZÀ - Guerrear (35).

MASICHI - Milho (50).

ME - Osso, jenipapo (16); cuidar, julgar (74).

MÈ - Falar (33), dizer (73).

MECA - Sinal no corpo (24).

MEHI! - Ora-sús! (Lat. AGE, AGEDUM, exclamantis) (97).

MEPEDİ - Levantar falso, aleive $(35,79)$.

MERÀ - Campo (16).

MERATÀ - Ferro (16).

MEREBÀ - Jirau para moquém (24).

MINEHE $^{\mathrm{n}}$ - Hoje, pelo tempo que já passou (93).

MÒ - In, ad, per, super (86).

MODÈ? - Aonde? Para onde? (88).

MOHOTÇÃ, MOHETÇÃ - Baldadamente (5, 93).

MOIGÜ - Aqui (93).

MOIGÜCHI - Até aqui (93).

MOIGÜDZÃ - (graf. MOIHÜDZÃ) - Aqui mesmo (93).

MOIGÜNÈ - Eis aqui (93).

MORÈ, MORECÙ - Logo, daqui a pouco (93).

MORI, MORINÈ - Assim, aí, desta maneira (Lat. HUJUSMODI) (88).

MORI, MORI - Uns e outros (Lat. CUM, TUM) (97).

MORÒ - Ser feito (30); assim (93).

MORO, MORONÒ - Basta (93).

MOROHÒ - Acolá, lá (93).

MU - Raiz (16).

MÙ, MUNETÈ - Curto (53).

MUCRI - Umbigo (16). 
MUDUCHİ - Gemer (28).

MUHÈ - Rede de pescar (16).

MUICÙ - Mandioca (60).

MURAWÒ - Porco (51), porco do mato (60).

MUTÈ - Opilação (1. 6).

MÜ - Tomar (70); levar (89), ser levado (grafado MY) (25); para a parte (Lat. VERSUS) (86).

MÜBÀ - Passar o rio (28).

MÜ BIHÈ MISÃ SAÍ - Cinco (6).

MÜCRIBÆ MISÃ IDEHÒ IBÜ SAÍ - Vinte (6).

MÜREPRÍ BUBIHÉ MISÃ SAÍ - Seis (6).

MÜREPRÍ WACHÁNI MISÃ SAÍ - Sete (6).

MÜREPRÍ WACHANIDIKIE MISÃ SAÍ - Oito (6).

MÜREPRÍ SUMARÃ ORÓBÆ MISÃ SAÍ - Nove (nesta expressão Mamiani omitiu a palavra MISÃ) (6).

MÜDÈ - Embrulhar-se o estômago (28).

MÜDZÈ - Peixe (57).

MÜGÜ - Contas (16).

MÜMÜCA - Fita (24).

MÜNHEDÀ - Ser levado recado aos ausentes (80).

MÜSÃ - Mão (20). Nos numerais encontra-se MISÃ.

MÜTÈ - Genro (24).

MÜTÈ - Trazer (73).

$\mathbf{N}$

NA - Trabalhar (77).

NABETCÈ - Esquecer (28), ser esquecido de alguém (81).

NÆMBI - Nariz (16).

NATÈ - Trabalhar (28). 
NE - Pescoço (16).

$\mathrm{NE}-$ Eis (90).

NÈ - Olhar $(33,80)$.

NÈ, NÙ - Claro (53).

NEBARÙ - Ombro (16).

NECÀ - Coisa guardada (16).

NECÒ, NECOTÒ - Arrotar (29).

NEMBÆ - Mudar-se de lugar (81).

NENÈ - Exclamação de quem cai na coisa (97).

NERÙ - Montão (95).

NERÙ - Mas (98).

NETÇÒ - Ser sabido (30); ver (69), ser visto (89).

NETÒ - Ser considerado (30); dar cuidado (80).

NETÒ, NETONGHI - Lembrar-se de coisa necessária (29).

NETONGHI - Ser necessário (80).

NEYENTÀ - Desejar $(29,79,80)$.

NHÀ - Morrer (29).

NHÆHI - Resgate (16); resgatar (79).

NHANHIKIE - Ter saudades (29).

NHE - Membro viril (16).

NHECARÀ - Fanhoso (16).

NHEDÈ - Escapar fugindo, escapar de alguém $(29,81)$.

NHENETİ - Ser lembrado (30).

NHEPRÙ - Crista de galo (17).

NHICORÒ - Ter preguiça (29), não ter vontade (79).

NHICRÆ - Ter vontade $(29,73,79)$.

NHIHÒ - Índio(s) (63).

NHIKÈ - Avó (17).

NHIKIENGHI (29) ou NHIHIENGHI (80) (?) - Causar dó, compaixão.

NHÙ - Mastigar (33). 
NHÙ - Menino (17).

NHÙ, NÙ - Filho (51).

NHUANHÀ - Sobrinho (17).

NHUPÜ - Vinho de milho (24).

NHUPÜTÈ - Instrumento de tirar fogo (24).

NIÒ- Fazer-se (76).

NO DEHE ${ }^{\mathrm{n}}$, NODE - E, também (97).

NÒ - A, ab, propter (de causa) $(19,86)$; se (conj.) (88); porque (Lat. QUIA, QUONIAM) (98).

NORI - Porque (Lat. QUONIAM) (98).

NORI...NE - Não (Lat. NE, adverbium vetandi) (88).

NÙ - Poder (verbo) (46).

NÙ - Claro (53).

NUNÙ - Língua (17).

NUSI - Determinar (35); tratar com alguém de alguma coisa (80).

$\mathbf{P}$

PÀ - Ser morto $(32,45)$.

PADZÙ - Pai $(13,17)$, amo (50).

PÆWI - Cachimbo (17).

PAIDENHÈ - Tio (17).

PANÜ - Cintilar (33).

PAYE $^{\mathrm{n}}$ - Tio (17).

PÈ - Pisar (33).

PEBAWITCETÒ - Engatinhar (33).

PEDÀ - Quebrar-se em pedaços (94).

PEHẼ - Tornar depressa (29).

PEHÒ - Enxurrar (29).

PEIPÈ, PEPÈ - Em migalhas (90). 
PENEHÒ - Em presença, à vista $(19,87)$.

PEPÈ - Pela de jogar (24).

PEPETÈ - Palma do pé (17).

PERÈ - Sair (33).

PERÈ - Ser contado, narrado $(80,100)$.

PERETÒ - Ser nomeado (80).

PETÓ - Manquejar (33).

PI - Casar (63).

Pİ - Estar (33). // PIDE - Está aí (95).

PI, PINETİ - Pequeno (53).

PITÈ - Rede (17, 85).

PIWONHÈ - Casamento (80), casar-se (81).

PÒ - Olho (17, 51). // PÒ IBÒ - Cotovelo (olho do braço) (52).

PO - Ser espancado, bater (90).

POBEBÀ - Fogaça (24).

POHÀ - Secar-se a raiz (33).

PÔHÔ - Varge (17).

PONHÈ - Desonesto (17); fazer desonestidades (81); andar de amores (80).

PONHÙ - Nadar (29).

POPÒ - Irmão mais velho (17).

POPONGHI - Roca de fiar (24).

POTÇÒ - Acordar (29).

POTE - Cortar (90).

POTÙ - Medonho (17), ser medonho (80).

PREBÙ - Cuieté (17).

PRENHÈ - Fígado (17).

PRETORE - Mentiroso (24).

PRI - Sangue (17).

PRI - Deixar (70).

PRIBÆ - Totalmente (88). 
PRODENHÈ, PRODENHÈMÜ - Além (87).

PROH - Oxalá (91); ainda que (98).

PROWI - Cair a árvore (33).

PUIPÙ - Fumegar (33).

PURÙ - Flor (17).

PÜ - Capim (3).

PÜCÀ - Banco (17).

$\mathbf{R}$

RADA - Chão (77).

RADAMÜ - Debaixo, para baixo, dentro (93).

$\mathrm{R}$ Æ - Macho (17).

RAE ${ }^{\mathrm{n}} \mathrm{BÒ}$ - Acenar com a mão (80).

RÆMÜ - Ai! coitado! (Lat. HEU, aut VAE, miserantis; voz de mulher) (97).

RÈ - Agastar-se (29, 80).

RENDÈ - Amigo, camarada (50, 64).

RENGHE (graf. RHENGE) - Velho (2).

RENGHE - Marido (24).

RERÈ - Pouco (90).

RI - Serrar (52).

RI - "se ajunta às vezes por elegância às perguntas: ut, SODERI ICOTÒ, por que furtou? Também significa fazer em outra parte a ação significada pelo verbo: ut, WIRI, ir para outra parte" (95).

RINÈ - Carne salgada (24).

RI...NÈ - Não (Lat. NE, adverbium vetandi) (88).

RÒ - Vestido (17, 60); partícula de elegância (95).

ROHÒ - Aquele // ROHÓÁ - Aqueles (gente) (9).

RONÈ - Continuamente (91).

RU - Partícula que "denota hábito, costume: ut, COTIRÙ, Ladrão que costuma furtar” (sic) (95). 
RUNHÙ - Panela (17).

RUTÈ - Velha, mulher (24).

S

S- - Ele, dele (11).

S...A - Eles, deles (11).

SÀ - Gordura (17); nascer (33).

SABUCÀ - Galinha (61).

SACRÈ - Rasgar-se (29).

SADÀ - Espingarda (17); secar, estalar (33).

SÆRÆ - Querer (46).

SAIBAMÜ - "Em parte baixa, como sobrado, ou atrás do outeiro" (sic) (93),

SAIBÒ - Sovaco (17).

SÃICRÒ - Arrebantar as plantas

SAIDÈ? - A que? Para que? (83).

SAIPRİ - Saltar (33).

SÂMBÀ - Cagado (4).

SAMBÜYÈ - Na verdade (93).

SANÈ - Matéria (17).

SANHICRÃ - Monte mor de coisas comestíveis (24).

SASÀ - Saia de pindoba (24).

SE - Senhor, amo (17, 65); ele, dele (11).

SE...A - Eles, deles (11).

SEBÈ - Cobertura (51).

SEBÒ - Transbordar o que ferve (33).

SEBÜ - Cadeiras (24).

SEKIKI - Carimã (24).

SEMÜMÜ - Guindar-se (35).

SERIDZÈ - Arco (24). 
SETI - Cordão (24).

SETÙ - Cesto (24).

SEWİ - Transbordar rio (34).

SI - Coração (17).

SI - Ele, dele (11). SI...A - Eles, deles (11).

SINEKIÈ - Às escuras (93).

SINHÃ - Sucessor (17).

SIRIRITE - Serra (52).

SIRIYANETÈ - Afiado (52).

SÒ - A, contra (87).

SÕ ou Õ? - Morder. - Na frase: NO HIWI MO BECHE ${ }^{\mathrm{n}}$ SÕ HIETÇÃ NO WÒ indo para a roça me mordeu uma cobra (74). Talvez - ser mordido.

SÒDE? - Por que? (Lat. CUR, QUARE) (88).

SODÈ? - Que? (56).

SODEWÒ? - Que modo é este? (Lat. HUI, respondentis cum modestia) (97).

SODEYÒ? - Quantas vezes? (Lat. QUOTIES) (88).

SOMBÜ - Pendão do milho (18).

SONCÒ - Urina (18).

SONDE - Testículos (18).

SONGÀ - Penas novas (18).

SORÒ - Enquanto (88).

SU - Ele, dele (11); fogo, lenha (25). SU...A - Eles, deles (11).

SUDÀ - Entrepor-se a alguma coisa (81).

SUMARÃ ORÓBÆ - Quatro (6).

SUTÙ - Fruta (53).

T

TÀ - Antes que (90).

TÀ - Pegar (91). 
TAMÜ - Aguilhada (24).

TANE - Desejar fumo (29).

TAPANHÙ - Negro (homem) (36).

TAPRİ - Arrebentar fio (34).

TASI - Enxada $(24,37)$.

TAYÙ - Dinheiro (24).

TÇÀ - Coisa moída, pisada (24).

TÇÃ - Duro (53); tesamente, rijamente, apertadamente (91); eu (96, 71).

TÇAHÒ - Estrepar-se (34).

TÇAMBÙ - Cabeça (18).

TÇATE - Cortar (2).

TCERERÒ - Gaita (18).

TCETÀ - Miolos (18).

TCETÒ - Corcovado (18).

TCICRÆ - Arrepiar-se o cabelo (29).

TCIHÈ - Fel (18).

TÇOHÒ - Muitos (6); haver (29), ter (75).

TÇÕHÒ - Homem, gente (18).

TÇONCÀ - Ponta (18).

TÇONCUPÜ - Cachaporra (18).

TÇUIRÙ - Assobio de rabo de tatu (24).

TE - Sobrinho, neto (18); designativo de plural com os nomes de parentesco e de gente $(6,95)$.

TE, TÈ - Vir $(29,46)$.

TEHATÈ - Ilharga (18).

TEIPRI - Artéria (18).

TEKÈ - Neta (18).

TENHÀ - Sobrinha (18).

TERERE - Corrupio (24).

TEUDIOKIÈ - Lutar (34). 
TI - Botar (90).

TIDACRÙ - Fazer cortesia (29).

TIDIE - Embarrar (34).

TIDZEHEHOBÒ - Relâmpago (18).

TIDZI - Mulher, fêmea (55, 95, 98).

TIDZÒ - Chover (34).

TIHIWI - Alevantar-se e ir-se (34).

TINGHI - Canafrecha (18).

TINHÈ - Alcofa (24).

TINHECÙ - Chuviscar (34).

TITİ - Tremer (21).

TÒ - Avó (18); preparar-se, ser preparado (77); muitas vezes, importunamente (91); partícula que torna os verbos frequentativos (95).

TÒ, TOTÒ - Redondo (53).

TOBÀ - Ser mostrado com a mão (80).

TOCRACÙ - Marca de ferro (24).

TODI - Estar em pé (34); ficar esperando, (77); estar em campo contra ou em presença de alguém (80).

TOPRÒ - Desmentir-se (34).

TORÀ - Cortesia com o pé (24), fazer cortesia (35).

TORARÃ - Carta, livro (25).

TOTONGHI - Bordão (25).

TOWANHIDÒ - Atolar (29).

TUDENHÈ - Nos tempos passados, dantes (93).

TUPÃ - Deus $(4,6)$.

TUYÒ - Zombar de alguém (80).

TUYOKIÈ - Passear (29).

TÜ - Descer abaixo (29). 
UANHI - Lavoura (60).

UBÀ - Dádiva (61).

UBETÈ - Reconhecer (79).

UBI - Ver (79).

UBÒ - Frutas colhidas verdes para amadurecer em casa (60).

UBUKERI - Agourar mal (79).

UBUMANÀ - Planta (vegetal) $(51,76)$.

UCÀ - Amar $(34,79)$.

UCRI - Mangaba (60).

UDÈ - Coisa cozinhada (59).

UDJE? - Que? (56).

UDJÈ - Legume (60).

UDJEINGHI? - Quando? (93).

UDZA - Faca (99).

UI - Ter cópula (81).

UIBÒ - Vomitar (79). (Grafado VIBÒ).

UINÙ - Rapaz (6), menino (78). (Ambos grafados VINÜ).

UITÒ - Coisa achada (60).

UKEMBI - Tomar erro, enganar-se (79).

UKISI - Repartição (60).

UNÀ - Repartir (79).

UNÆ - Sonhar $(74,81)$.

UNÉ - Saber fazer (79).

UNÈ - Saber fazer (79).

UNÙ - Dormir (56, 66); doer (80).

UPEBAWI - Rastejar; recordar consigo (79).

UPODÒ - Coisa assada (60).

UPRÈ - Mentir (79). 
URÒ - Isso (9).

USARUNGUWONHÈ - Desposar-se (81).

USE - Alegrar-se (79).

UTÇOTÇOHÒ - Zombar (79).

UWANHI - Ter mister (79).

UWÒ - Cunhado (22).

\section{W}

WACHÁNI - Dois, segundo $(6,53)$.

WACHÁNIDIKIÈ - Três, terceiro $(6,53)$.

WAKIÈ - Faltar (29).

WANDÜ - Não há $(73,91,95)$.

WANHERÈ - Fazenda $(18,94)$.

WANHIDÒ - Esconder-se atrás de uma moita (29).

WANHUBATÇÃ - Quinhão, repartição $(18,60)$.

WARÆRÒ - Beijú (25).

WARANDZI - Mesinha (25).

WARARÃ - Instrumento de tanger (18).

WARE - Padre $(3,57)$.

WARIDZÀ - Boca (25).

WARUÀ - Espelho (18).

WARUDÙ - Bolo de mandioca assada (25).

WASÙ - Esquerdo (18).

WATCÈ - Ser botado pregão (80).

WATİ - Azedo (20).

WAWÃDÀ - Jejuar (29).

WERETÈ - Prato para fazer louça (25).

WI - Ir (29, 34); fazer-se (Lat. EVADERE) (79).

WIDÒ, WIDÒBAE - Só, sobretudo, mais que tudo (58). 
WIMA - Abano (25).

WINÈ - Acenar com a. cabeça $(29,80)$.

WINÙ - Atrever-se (79).

WIPOKIÈ - De revés (93).

WIRAPARARÃ - Engenho de moer (25).

WIRÈ - Combetear (?) (34).

WÒ - Caminho (18); caminhar (46).

WÒ - Cobra (?). Na frase: NO HIWI MO BECHEn SÕ HIETÇÃ NO WÒ - indo para a roça, me mordeu uma cobra (74), "partícula que, entreposta na oração, denota enfadamento de quem fala" (96).

WÕ - Perna (18).

WOBOHÒ - Após, atrás $(19,87)$.

WODICÒ - Brigar (30).

WODÒ - Bêbado (18), embebedar-se (30).

WOHOYE $^{\mathrm{n}}$ - Todos, (52).

WOIBIHO - Somente (93).

WOICRÆ - Cavalgar pau (30).

WOICRÆBAHÀ. - Aboiar (30).

WONCURÒ - Tear (25).

WONGHEBÜ - Perder-se no caminho (34), andar errado do caminho (81).

WONGHECRI - Endoidecer, ser doido (29).

WONGHERÈ - Pobre (18).

WONHÈ - Bem, perfeitamente (91).

WONHEHÈ - Debaixo $(19,87)$.

WONHÙ - Ter ciúmes $(30,80)$.

WORÈ - Braço de caminho, rio, etc. (19).

WORÒ - Costas (19).

WOROBÜ - Novas (25); contar (35).

WOROMÜ - Detrás das costas (93).

WORONÈ - Intérprete (19); interpretar (79); inteligivelmente, claramente (91). 
WOROYA - Espia (25).

WOROYENTA - Admirar o que se vê (35); ver com admiração (graf. WORYOENTÀ) (79).

WOYÈ - Seço (?) (18).

WOYÈN - Tapuias bravos (4).

Y

YA - Eia! (Lat. AGE, AGENDUM, sollicitantis; voz de homem) (97).

YACÀ - Cachorro (96).

YACHI - Grande (96).

YACÒ - Enfastiar-se $(28,79)$.

YACRÈ - Bocejar (33).

YACRİ - Arreganhar os dentes (33).

YACRORÒ - Anzol (16).

YÆHÈ - Sobrinha (16).

YÆNTÀ - Taquara (16).

YAHÈ - Ai (Lat. HEI, dolentis; voz de homem) (97).

YAHI - Ser concebido (30).

YANÈ - Afiado (99).

YARIDZI - Espora (23).

YARÙ - Priaca frecha (?) (16).

YAWÒ - Gancho (23).

$\mathrm{YE}^{\mathrm{n}}$ - Grande (53).

YEMÜ - Arriba, em cima (92).

YEWÒ - De graça, gratuito (90).

YÒ - Muitos (53); frequentemente, muitas vezes (90).

YUH, YUHYA, YUHYÀRETÈ - Ui! (Lat., HUI, admirantis) (97). 